\title{
Regulation of the plastochron by three MANY-NODED DWARF genes in barley
}

5 Ken-ichiro Hibara1, Masayuki Miya ${ }^{2}$, Sean Akira Benvenuto², Naoko Hibara-Matsuo ${ }^{1}$, Manaki

6 Mimura $^{3}$, Takanori Yoshikawa ${ }^{4}$, Masaharu Suzuki ${ }^{5}$, Makoto Kusaba $^{6}$, Shin Taketa ${ }^{7}$ and Jun-ichi Itoh ${ }^{2 *}$

$8{ }^{1}$ Graduate School of Agricultural Regional Vitalization, Kibi International University, Minamiawaji,

9 Hyogo, 656-0484, Japan

$10{ }^{2}$ Graduate School of Agricultural and Life Sciences, University of Tokyo, Tokyo, 113-8657, Japan

$11{ }^{3}$ National Institute of Genetics, Mishima, Shizuoka, 411-8540, Japan

$12{ }^{4}$ Graduate School of Agriculture, Kyoto University, Kyoto, 606-8502, Japan

$13{ }^{5}$ Horticultural Sciences Department, University of Florida, Gainesville, Florida, 32611 USA

$14{ }^{6}$ Graduate School of Integrated Sciences for Life, Hiroshima University, Higashi-Hiroshima, Japan

$15{ }^{7}$ Group of Genetic Resources and Functions, Institute of Plant Science and Resources, Okayama

16 University, Kurashiki, Okayama, 710-0046, Japan

$18 *$ Corresponding author:

19 E-mail: ajunito@g.ecc.u-tokyo.ac.jp 


\section{Abstract}

The plastochron, the time interval between the formation of two successive leaves, is an

3 important determinant of plant architecture. We genetically and phenotypically investigated manynoded dwarf (mnd) mutants in barley. The mnd mutants exhibited a shortened plastochron and a decreased leaf blade length, and resembled previously reported plastochron1 (pla1), pla2, and pla3 mutants in rice. In addition, the maturation of $m n d$ leaves was accelerated, similar to pla mutants in rice. Several barley $m n d$ alleles were derived from three loci- $M N D 1, M N D 4$, and $M N D 8$. Although

8 MND4 coincided with a cytochrome P450 family gene that is a homolog of rice PLA1, we clarified 9 that $M N D 1$ and MND8 encode an N-acetyltransferase-like protein and a MATE transporter-family 10 protein, which are respectively orthologs of rice GW6a and maize BIGE1 and unrelated to PLA2 or

$11 P L A 3$. Expression analyses of the three $M N D$ genes revealed that $M N D 1$ and $M N D 4$ were expressed

12 in limited regions of the shoot apical meristem and leaf primordia, but $M N D 8$ did not exhibit a specific

13 expression pattern around the shoot apex. In addition, the expression levels of the three genes were

14 interdependent among the various mutant backgrounds. Genetic analyses using the double mutants

$15 m n d 4 m n d 8$ and $m n d 1 m n d 8$ indicated that $M N D 1$ and $M N D 4$ regulate the plastochron independently

16 of MND8, suggesting that the plastochron in barley is controlled by multiple genetic pathways

17 involving $M N D 1, M N D 4$, and $M N D 8$. Correlation analysis between leaf number and leaf blade length

18 indicated that both traits exhibited a strong negative association among different genetic backgrounds

19 but not in the same genetic background. We propose that MNDs function in the regulation of the

20 plastochron and leaf growth and revealed conserved and diverse aspects of plastochron regulation via 21 comparative analysis of barley and rice.

\section{Author summary}

The number of leaves produced during a plant's lifetime is major determinant of plant architecture and affects the efficiency of photosynthesis and crop productivity. The leaf number is 
1 dependent on the temporal pattern of leaf initiation at the shoot apical meristem, which is termed the

2 plastochron. The genetic factors involved in plastochron regulation have been identified in several

3 plant species. However, whether the functions of plastochron-related genes and their genetic pathways

4 are universal or diversified among different plant species is unclear. In this study, we investigated

5 many-noded dwarf (mnd) mutants in barley, which exhibited a shortened plastochron and a decreased

6 leaf blade length. The mutant alleles used in this study were derived from three loci, $M N D 4, M N D 1$, and $M N D 8$, which encode a cytochrome $\mathrm{P} 450$ family protein, an $\mathrm{N}$-acetyltransferase-like protein, and

8 a MATE transporter-family protein, respectively. Phenotypic and expression analyses revealed that

9 these three MND genes affect the leaf production rate and leaf maturation program, but their

10 expression levels were interdependent. In addition, the plastochron and leaf growth are closely related

11 but independently regulated. We also analyzed the expression patterns and knockout mutants of rice

$12 M N D$ orthologs to clarify whether their biological functions are conserved in rice and barley. This

13 study provides insight into the genetic mechanisms of plastochron control in grass species.

\section{Introduction}

The spatiotemporal pattern of leaf initiation is a major contributor to the formation of plant

17 architecture. The temporal pattern of leaf initiation is termed the plastochron; that is, the time interval

18 between the initiation of two successive leaf primordia. The spatial pattern of leaf initiation along the

19 shoot axis is referred to as phyllotaxy. Both patterns of leaf initiation are determined by the activity of

20 the shoot apical meristem (SAM), which is the source of leaf primordia [1, 2]. Although the

21 plastochron and the phyllotaxy are sometimes regulated by shared genetic components operating at

22 the SAM, some genes are specific to one or the other of the patterns $[1,3]$.

24 Loss of function of PLAl causes rapidly emerging small leaves, resulting in more than twice the number of leaves compared to the wild type (WT). PLA1 encodes a plant-specific cytochrome P450 
1 family protein, CYP78A11 [5]. Arabidopsis KLU is also a CYP78A-family member and its loss-of-

2 function mutant exhibits accelerated leaf initiation and produces small organs [6]. PLA2 is another

3 plastochron-regulating factor in rice [7]. PLA2 encodes a MEI2-like RNA-binding protein, which is

4 an ortholog of TERMINAL EARl (TE1) in maize (Zea mays) [8]. Although TE1 plays a role in the

5 regulation of phyllotaxy, accelerated leaf initiation in the loss-of-function mutant is shared between

6 te1 and pla2. PLA3 has also been reported to regulate the plastochron. A loss-of-function mutant of

$7 \quad$ PLA3 exhibits not only a shortened plastochron but also pleiotropic phenotypes such as embryonic

8 defects [9]. PLA3 encodes a homolog of glutamate carboxypeptidase, which dissociates glutamate

9 from small peptides [9]. PLA3 is the rice ortholog of Arabidopsis ALTERED MERISTEM PROGRAMI

10 (AMP1) [10] and maize VIVIPAROUS8 [11]. Consequently, in rice, loss-of-function mutants of three

11 PLA genes share the phenotypes of rapid leaf production, small leaf size, and aberrant inflorescence

12 structure $[4,7,9]$.

SQUAMOSA PROMOTER BINDING PROTEIN-LIKE (SPL) genes are plant-specific

14 transcription factors, some of which are negatively regulated by $m i R 156$ [12-15]. SPL genes are also

15 involved in plastochron regulation. A double loss-of-function mutant of AtSPL9 and AtSPL15 in

16 Arabidopsis exhibited a short plastochron [6, 16]. Conversely, the expression of an miR156-resistant

17 form of $S P L 9$ caused a prolonged plastochron [6]. In grass species such as rice and maize, $S P L$ genes

18 and $m i R 156$ have conserved functions in plastochron regulation. Accumulation of $O S S P L$ transcripts

19 caused a prolonged plastochron in rice and loss-of-function mutants of several SPL genes and plants

20 overexpressing miR156 exhibited a short plastochron in both rice and maize [17-23].

The big embryol (bigel) mutant in maize exhibits an increased leaf and seminal root number in addition to a large embryo [24]. BIGE1 encodes a MATE-type transporter that likely plays a role in

23 the secretion of an unidentified small molecule in the trans-Golgi. BIGE1 function is conserved

24 between maize and Arabidopsis, because both single and double mutants of BIGE1 homologs in 25 Arabidopsis produced an increased number of leaves, and the introduction of BIGE1-GFP fusion genes 26 into an Arabidopsis bige1 mutant partially complemented the mutant phenotype [24]. 
Despite the identification of genes involved in the plastochron, the relationships among these

2 genes and genetic pathways in plastochron regulation are unclear. In Arabidopsis, KLUH/CYP78A5 and AtSPL9/miR156 affect the plastochron and organ size in parallel genetic pathways [6]. In rice, a pla1 and pla2 double mutant exhibited enhanced phenotypes compared with each single mutant, suggesting that PLA1 and PLA2 function in independent pathways [7]. Although maize BIGE1 is involved in the feedback regulation of a CYP78A pathway, the phenotypic effect of the interaction on the plastochron has not been elucidated [6]. In addition to the genetic pathways, knowledge of 8 functional conservation of plastochron-related genes among plant species is fragmentary. Barley (Hordem vulgare) is an important cereal crop for which considerable genetic resources are available, including collections of morphological and developmental mutants [25]. In addition,

11 high-quality genome sequence information is available [26]. Thus, barley is an alternative model for 12 grass molecular genetics with a less gene redundancy and is suitable for comparative studies with the 13 other grass species. Here, we genetically and phenotypically characterized many-noded dwarf (mnd) 14 mutants in barley, which were originally described in the 1920s as dwarf mutants with many nodes 15 [27]. All mnd mutants exhibited a shortened plastochron, comparable to pla mutants in rice. We 16 identified the genes responsible for $m n d$ mutants and showed that the plastochron and leaf length are 17 independently controlled by three genetic factors- $M N D 1, M N D 4$, and $M N D 8$. Here, we propose to 18 assign a new gene symbol $m n d 8$ to a mutation that was found at a locus different from the seven 19 previously described $m n d$ loci in barley. We revealed that MND8 encodes a MATE transporter-family 20 protein, which is an ortholog of maize BIGE1. MND1 encodes an N-acetyltransferase-like protein that 21 reportedly regulates phase changes [28]. MND4 had been reported as a cytochrome P450-family gene and a homolog of rice PLA1 [29]. Our phenotypic and genetic analyses of the mnd mutants suggested

23 functions for the three $M N D$ genes and the existence of complex genetic interactions among them.

24 Furthermore, our comparative analysis of rice and barley clarified the diversity and conservation of 25 plastochron genetic pathways. 


\section{$1 \quad$ Results}

\section{$2 \quad$ Plastochron and phyllochron of mnd mutants}

The mnd mutants used in this study are listed in Table 1. Allelism tests revealed that these

4 mutants carried alleles derived from at least three independent loci, $M N D 1, M N D 4$, and $M N D 8$ (Table

5 1). MND4 is also known as HvMND [29]. Among the mutants, three-OUM165, OUM169, and

6 OUX051 - which are presumed to contain the alleles $m n d 8_{\mathrm{OUM} 165}$, mnd $4_{\mathrm{OUM} 169}$, and $m n d l_{\mathrm{OUX} 051}$,

7 respectively, and Akashinriki, an original cultivar of OUM165 and OUM169, were subjected to

8 detailed genetic and phenotypic analyses.

9

10 Table 1. mnd mutants used in this study

\begin{tabular}{|c|c|c|c|c|}
\hline Strain & $\begin{array}{c}\text { Allele } \\
\text { determined } \\
\text { by allelism } \\
\text { tests }\end{array}$ & $\begin{array}{l}\text { Allele / mutation } \\
\text { by sequencing }\end{array}$ & $\begin{array}{l}\text { Mutation effect } \\
\text { on protein }\end{array}$ & $\begin{array}{c}\text { Background } \\
\text { cultivar }\end{array}$ \\
\hline OUM165 & mnd8 & $m n d 8 / \mathrm{T} \rightarrow \mathrm{C}$ & $\mathrm{L} \rightarrow \mathrm{P}$ & Akashinriki \\
\hline OUM166 & n.d. & $m n d 8 / \mathrm{G} \rightarrow \mathrm{A}$ & $\mathrm{G} \rightarrow \mathrm{N}$ & $?$ \\
\hline OUM168 & n.d. & mnd $8 / \mathrm{G} \rightarrow \mathrm{A}$ & $\mathrm{G} \rightarrow \mathrm{N}$ & $?$ \\
\hline OUM169 & mnd4 & $m n d 4 / \mathrm{G} \rightarrow \mathrm{A}$ & $\mathrm{G} \rightarrow \mathrm{D}$ & Akashinriki \\
\hline OUX051 & mndl & mnd1 / 8bp insertion & Turncated & Mesa \\
\hline SM5 & mndl & mndl / 1bp deletion & Turncated & Kanto Nijo 29 \\
\hline SM6 & mndl & mndl / 1bp deletion & Turncated & Kanto Nijo 29 \\
\hline GSHO253 & mndl & mnd1 / 8bp insertion & Turncated & Mesa \\
\hline GSHO2038 & n.d. & $m n d 1 / 8 \mathrm{bp}$ insertion & Turncated & Bowman \\
\hline GSHO2135 & n.d. & $m n d 4 / \mathrm{G} \rightarrow \mathrm{A}$ & $\mathrm{R} \rightarrow \mathrm{K}$ & Bowman \\
\hline GSHO1798 & n.d. & $m n d 4 / \mathrm{G} \rightarrow \mathrm{A}$ & $\mathrm{R} \rightarrow \mathrm{K}$ & Akashinriki \\
\hline NGB1 14540 & n.d. & mnd $1 / \mathrm{G} \rightarrow \mathrm{T}$ & $\mathrm{R} \rightarrow \mathrm{L}$ & Kristina \\
\hline NBG114547 & n.d. & $m n d 8 / \mathrm{T} \rightarrow \mathrm{A}$ & $\mathrm{W} \rightarrow \mathrm{R}$ & Bonus \\
\hline NGB117205 & n.d. & $m n d 8 / \mathrm{G} \rightarrow \mathrm{A}$ & $\mathrm{G} \rightarrow \mathrm{E}$ & Bonus \\
\hline
\end{tabular}

11 n.d. : not determined.

First, we evaluated the vegetative phenotypes. The three $m n d$ mutants produced more leaves

14 than Akashinriki at all stages of vegetative development (Fig 1A-1D). However, the extent of leaf 
emergence varied among the mutants and growth stages. In the WT and $m n d s$, leaf emergence was slow in the early vegetative phase and rapid in the late vegetative phase (Fig 1E). At 40 days after germination, the number of leaves that emerged in $m n d 8_{\text {OUM } 165}$ and $m n d l_{\text {OUX051 was twofold that in }}$ the WT, and that in $m n d 4_{\text {OUM169 }}$ was intermediate between those of the WT and other mutants, indicating that the three mutants have an increased leaf production rate (Fig 1E).

Fig 1. Vegetative phenotypes of $\boldsymbol{m n d}$ mutants. (A-D) Seedlings of the wild-type and mnd mutants at 1 month after germination. (A) Akashinriki, (B) mnd8 ${ }_{\text {OUM165 }}$, (C) $m n d 4_{\text {OUM169, }}$ and (D) $m n d 1_{\text {OUX051 }}$.

(E) Changes in leaf number during vegetative development.

Two indices represent the temporal pattern of leaf production, the plastochron and the phyllochron [30]. The plastochron is the time interval between two successive leaves produced at the

13 SAM, and the phyllochron is the time interval between two successive leaves emerging from the top

14 of the former leaf sheath. Although the plastochron and phyllochron are equal in rice, the plastochron 15 is shorter than the phyllochron in most other cereal crops [30]. To calculate the plastochron, we 16 observed shoot apices of the WT and three mnd mutants at 1 and 2 weeks after germination (WAG)

17 (S1 Fig). In most shoot apices of Akashinriki at $1 \mathrm{WAG}$, the P1 primordium was the fifth leaf 18 protruding from the SAM (S1A Fig). At 2 WAG, the P1 primordium was the seventh leaf in most 19 Akashinriki shoot apices (S1E Fig). Therefore, two new leaf primordia were produced from the SAM 20 over 1 week in Akashinriki. In the mnd mutants, most of the P1 primordia were fifth leaves at 1 WAG, 21 but eighth leaves at 2 WAG (S1B-1D, S1F-H Fig). The plastochrons of the three mnd mutants were shorter than that of the WT (Table 2). We also calculated the phyllochrons for the four growth periods.

23 For the first period from 1 to 2 WAG, the phyllochron was longer than the plastochron in the WT and 24 mnd mutants. Although the phyllochrons in the WT and $m n d \mathrm{~s}$ became shorter in the later periods, the 25 difference between the WT and $m n d$ s increased, suggesting that the leaf production rates of $m n d$ mutants increased at later developmental stages. These results suggested that the three mnd mutants 
were defective in plastochron control, although the plastochron was shorter than the phyllochron in both the wild-type and $m n d$ mutants.

Table 2. Characterization of leaf production and leaf emergence rate in mnd mutants

\begin{tabular}{|c|c|c|c|c|}
\hline & Akashinriki & mnd $8_{\text {OUM } 165}$ & mnd $4_{\text {OUM } 169}$ & mnd $1_{\text {OUX } 051}$ \\
\hline Leaf number of P1 stage at $1 \mathrm{WAG}^{\mathrm{a}}$ & $5.0 \pm 0.0$ & $5.2 \pm 0.4$ & $5.0 \pm 0.0$ & $5.8 \pm 0.4$ \\
\hline Leaf number of P1 stage at $2 \mathrm{WAG}^{\text {a }}$ & $7.2 \pm 0.4$ & $8.0 \pm 0.0$ & $8.0 \pm 0.0$ & $9.2 \pm 0.4$ \\
\hline $\begin{array}{l}\text { Plastochron during 1-2 WAG } \\
\text { (days/leaf production) }^{\text {a }}\end{array}$ & $3.2 \pm 0.7$ & $2.5 \pm 0.4$ & $2.3 \pm 0.0$ & $2.0 \pm 0.4$ \\
\hline $\begin{array}{l}\text { Phyllochron during 1-2 WAG } \\
\text { (days/leaf emergence) }^{\mathrm{b}}\end{array}$ & $5.6 \pm 0.1$ & $4.3 \pm 0.6$ & $6.4 \pm 0.2$ & $3.0 \pm 0.3$ \\
\hline $\begin{array}{l}\text { Phyllochron during 1-2 WAG } \\
\text { (days/leaf emergence) }^{\mathrm{b}}\end{array}$ & $6.9 \pm 0.1$ & $3.1 \pm 0.7$ & $5.2 \pm 0.2$ & $3.0 \pm 0.4$ \\
\hline $\begin{array}{l}\text { Phyllochron during 1-2 WAG } \\
\text { (days/leaf emergence) }^{\mathrm{b}}\end{array}$ & $6.9 \pm 0.1$ & $3.0 \pm 0.7$ & $5.4 \pm 0.2$ & $2.9 \pm 0.7$ \\
\hline $\begin{array}{l}\text { Phyllochron during 1-2 WAG } \\
\text { (days/leaf emergence) }^{\mathrm{b}}\end{array}$ & $5.3 \pm 0.3$ & $1.9 \pm 0.7$ & $2.6 \pm 0.5$ & $2.4 \pm 0.8$ \\
\hline
\end{tabular}

WAG: week after germination. a: Calculated by the P1 leaf primordium of the shoot sections as shown in S1 Fig $(n=5)$. b: Calculated by the leaf emergence change as shown in Fig 1E $(n=5)$.

8 Growth and cell-division pattern of $m$ nd leaf primordia

An increased leaf production rate may alter the spatial relationship among leaf primordia in

10 the $m n d s$. In other words, a rapid leaf production in the $m n d$ s may change the number of leaf primordia

11 inside a leaf primordium at the same developmental stage. To assess this, we examined the shoot apices

12 of the mnd mutants at 2 WAG under an electron microscope (S1 Fig and Fig 2). The relationships

13 between successive leaf primordia in the $m n d$ s were similar to that in the WT. Namely, when the P1

14 leaf primordium protruded from the flank of the SAM, the P4 leaf primordium gradually enclosed the 
1 inner leaf primordia in the WT (Fig 2A and 2B), and this relationship was conserved in the three mnd

2 mutants (Fig 2C and 2F).

Fig 2. Spatial relationship between leaf-primordium stage and cell-division activity in mnd

mutants. (A, C-F) Scanning electron micrographs of the shoot apex of mnd mutants at 2 weeks after germination. (A) Shoot apex of Akashinriki. (B) Longitudinal section of the shoot apex of Akashinriki corresponding to (A). Shoot apices in $m n d 8_{\text {OUM165 }}(\mathrm{C}), m n d 4_{\text {OUM169 }}(\mathrm{D})$, and $m n d 1_{\text {OUX051 }}(\mathrm{E})$. (F) Shoot apex of $m n d 1_{\text {OUX051 }}$ from which the $6 \mathrm{~L} / \mathrm{P} 4$ primordium was removed. $\mathrm{xL}$ indicates the $\mathrm{x}^{\text {th }}$ leaf and Px

9 is the order of leaf emergence from the shoot apical meristem. (G-J) Expression pattern of histone $H 4$

10 in the shoot apex of wild-type and mnd mutants at 10 days after germination according to in situ

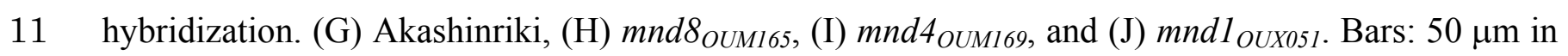
$12 \quad \mathrm{~A}-\mathrm{F}$ and $200 \mu \mathrm{m}$ in $\mathrm{G}-\mathrm{J}$.

To understand the growth pattern of leaf primordia in the $m n d \mathrm{~s}$, cell division around the shoot apex was investigated by in situ hybridization using the cell-division biomarker histone $H 4$ (Fig 2G2J). The number of histone $H 4$ signals around the shoot apex in the $m n d$ mutants was generally higher compared with the WT. In particular, histone $H 4$ signals in the $m n d l$ were remarkably increased (Fig $2 \mathrm{G}$ and $2 \mathrm{~J})$. However, patterns of density of histone $H 4$ signals in the $m n d 4$ and $m n d 8$ mutants were similar to that in the WT; namely, cell division activity was relatively low at P1 to P4 and enhanced in P5-stage leaf primordia in the WT, mnd4, and mnd8. Therefore, stage-specific developmental events

21 in leaf primordia in the $m n d 4$ and $m n d 8$ are likely unchanged, although leaf stage progressions could be more accelerated in the $m n d 1$. Thus, the barley $m n d$ s exhibited not only rapid leaf production but also rapid leaf development, as do pla mutants in rice [7]. 
The three $m n d$ mutants exhibited similar phenotypes, and the affected traits were comparable

2 to those of pla mutants in rice. Accordingly, the three $M N D$ genes in barley could be counterparts of

3 the three rice $P L A$ genes $[5,7,9]$.

To identify the three $M N D$ loci, we first determined the nucleotide sequences of MND4/HvMND (HOR5Hr1G081060) in OUM169, a homolog of rice PLA1 [29] (S2A Fig). We

6 detected a single nucleotide polymorphism between Akashinriki and $m n d 4_{\text {OUM169 }}$. The mutation was a

G-to-A single base change (G425A) causing a Gly-to-Asp amino-acid substitution in the first exon of

8 MND4 (Fig 3A, Table 1). This amino acid is conserved among angiosperms, suggesting it to be

9 responsible for the phenotype of $m n d 4_{\text {OUM169 }}$ (S3 Fig). We detected an identical mutation in the other

10 two $m n d$ mutants, $m n d 4_{\mathrm{GSHO}}{ }_{35}$ and $m n d 4_{\mathrm{GSHO} 1798}$, that caused an Arg-to-Lys amino-acid substitution,

11 which has been reported previously [29] (Fig 3A, Table 1, S3 Fig). Because we found multiple mnd4

12 alleles linked to a shortened plastochron phenotype, $M N D 4 / H v M N D$ regulates the plastochron in

13 barley.

15 Fig 3. Genomic structure of MND genes. (A-C) Genomic structure and mutation points of MNDs.

16 (A) $M N D 4$, (B) $M N D 8$, and (C) MND1. Boxes indicate exons, arrows indicate mutation points.

Next, to identify candidates for MND1 and MND8, we tested the barley ortholog of PLA2:

19 HvPLA2 (HORVU3Hr1G091930). Rice pla2 exhibits a phenotype similar to those of barley mnd

20 mutants [7]. We determined the nucleotide sequences of HvPLA2 in various mnd mutant and WT pairs.

21 A database search showed that HvPLA2 is located in barley chromosome $3 \mathrm{H}$, which is syntenic to rice

22 chromosome 1 carrying PLA2, but our mapping showed that MND1 and MND8 are located on

23 chromosomes $7 \mathrm{H}$ and $5 \mathrm{H}$, respectively. We found no mutation causing an amino-acid change or

24 frameshift in HvPLA2 in $m n d 8_{\mathrm{OUM} 165}$ and $m n d 1_{\mathrm{OUX} 051}$, suggesting that neither MND1 nor $M N D 8$ is 
A barley ortholog of rice pla3 was next investigated because of its similar phenotype [9]. The

2 barley ortholog of PLA3 (HORVU5Hr1G103900), HvPLA3 in rice chromosome 3, in located on

3 syntenic chromosome $5 \mathrm{H}$. We mapped $M N D 8$ to the distal region of the long arm of barley

4 chromosome $5 \mathrm{H}$, but this position deviated distally from the HvPLA3 candidate interval. No mutation

5 was detected in the nucleotide sequence of $H v P L A 3$ in mnd8 $8_{\mathrm{OUM} 165}$. Sequencing of $H v P L A 3$ in

$6 \quad m n d l_{\text {OUX051 }}$ revealed two point mutations causing amino-acid substitutions, and a six-base deletion

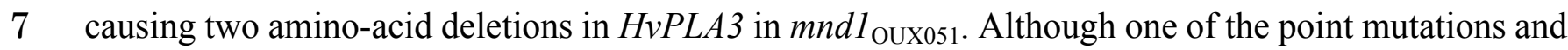

8 the deletion mutation did not change the amino acids conserved among angiosperms, a C-to-A point

9 mutation (C773A) in the first exon caused a Pro-to-Gln amino-acid substitution (P258Q) at a

10 conserved position (S6 and S7 Figs). However, we did not find nucleotide polymorphisms between

11 Akashinriki and the other $m n d$ mutants with $m n d 1$ alleles, i.e., $m n d 1_{\mathrm{GSHO} 253}$ and $m n d 1_{\mathrm{SM} 6}$. Based on

12 these inconsistent mapping and sequencing results, $H v P L A 3$ is not responsible for mnd1.

13 Because it is unlikely that MND1 and MND8 are HvPLA2 or HvPLA3, we searched for other

14 candidate genes that regulate the plastochron based on reports in species other than rice. Rough

15 mapping in barley showed that $m n d 8$ is located $2 \mathrm{cM}$ distal to the barley EST marker k08652 (syn.

16 HORVU5Hr1G112990), whose map position is $253.1 \mathrm{cM}$ in the distal region of the long arm of

17 chromosome 5H according to the EST map [31]. Around the mapped region, we found a candidate

18 gene, a homolog of $B I G E 1$, which regulates not only embryo size but also the leaf initiation rate in

19 maize [24]. We subsequently examined the nucleotide sequence of the BIGE1 homolog

20 (HORVU5Hr1G103900), which encodes a MATE transporter-family protein. We found a T-to-C

21 single base change (T3022C) mutation in the second exon of the gene in $m n d 8_{\text {OUM } 165}$ that caused a

22 Leu-to-Pro amino-acid substitution (L404P) (Fig 5B, Table 1, S4 Fig). The nucleotide sequence of the

23 gene in four mnd mutants-OUM166, OUM168, NBG114547, and NGB117205-revealed three

24 independent mutations causing amino-acid substitutions (G106E, W278R, and G298N) in the coding

25 region. Accordingly, we concluded that this MATE transporter-like gene is MND8. A phylogenetic 26 analysis indicated that MND8 is an ortholog of maize BIGE1 (S2 Fig). 
Next, we mapped mndl using publicly available simple sequence repeat (SSR) markers in

2 barley [32]. Barley mndl was located in the distal region of the long arm of barley chromosome $7 \mathrm{H}$,

3 flanked by the SSR markers GBM1419 and Bmac156. Using this map information, we searched for

$4 \quad$ mndl candidate genes. We identified as a strong candidate for MND1 (HORVU7Hr1G113480) a

5 homolog of HOOKLESS1 (HLS1), which encodes an N-acetyltransferase-like protein. Although there

6 are no reports on HLS1 homologs regulating the plastochron in Arabidopsis, multiple Arabidopsis

7 mutants of $H L S 1$ homologs exhibited excess leaf production and a small leaf size [33-35]. One HLS1

8 homolog in barley was located near the distal arm region of chromosome 7HL, where mndl was

9 mapped. Sequence analysis of this gene revealed that $m n d l_{\text {OUX051 }}$ carries an eight-nucleotide deletion

10 in the second exon starting at position 464, causing a frameshift and introducing a premature stop

11 codon (Fig 3C, Table 1, S5 Fig). Sequencing of four mnd mutants with the $m n d 1$ alleles $\left(m n d 1_{\mathrm{SM} 5}\right.$,

$12 m n d 1_{\mathrm{SM} 6}, m n d 1_{\mathrm{GSHO} 253}$, and $\left.m n d 1_{\mathrm{GSHO} 2038}\right)$ and one other $m n d$ mutant, NGB1 14540 , revealed an eight-

13 base insertion, two independent one-base deletions, and one amino-acid substitution in the coding

14 region (Fig 3C, Table 1, S5 Fig). In addition, among the mutations in $M N D 1$, the eight-base insertion

15 in $m n d l_{\mathrm{OUX} 051}, m n d l_{\mathrm{GSHO} 253}$, and $m n d l_{\mathrm{GSHO} 2038}$ was identical to that reported in $m n d 1 . a$ [28]. Therefore,

16 we concluded that this $H L S 1$-like gene is MND1. A phylogenetic analysis indicated that MND1 is an

17 ortholog not of $H L S 1$ but of GW6a, a quantitative trait locus that regulates grain weight in rice [36]

18 (S2 Fig).

Accordingly, the three $M N D$ genes—MND4, MND8, and MND1-encode CYP78A family,

20 MATE transporter-family, and N-acetyltransferase-like proteins, respectively.

\section{Expression pattern of the three $M N D$ genes}

To evaluate their regulation of the plastochron and leaf growth, the expression patterns of the

24 three MND genes around the shoot apex were investigated using in situ hybridization (Fig 4). MND4 
1 SAM was complex, with expression detected in small patches of the SAM flank. One patch was

2 observed at the boundary between the SAM and P1 leaf primordia. Strong MND4 expression was

3 observed in the basal part of the adaxial and abaxial sides of P1-P4 leaf primordia, including the

4 boundary between successive leaf primordia (Fig 4A). Expression of MND8 was weak in the SAM

5 and younger leaf primordia, and was not observed in the shoot apex (Fig 4B).

Fig 4. Expression pattern of the three $M N D$ genes in the shoot apex at 10 days after germination.

8 (A) MND4, (B) MND8, and (C) MND1. The P1-P4 leaf primordia are labeled. Arrowheads indicate

9 gene expression at the boundaries between leaf primordia. The dashed arrow in (A) indicates

10 expression at the boundary between the shoot apical meristem and P1 leaf primordium. Two-headed

11 arrows indicate expression at the leaf base. Note the relative position of expression at the leaf base

12 differs between (A) and (C). Bars: $200 \mu \mathrm{m}$.

The expression pattern of MND1 was similar to that of MND4; that is, expression was

15 observed in small patches of the SAM and the basal part of leaf primordia (Fig 4C). However, the area

16 of expression was not identical to that of MND4. First, MND1 expression was detected not at the

17 boundary between the SAM and P1 leaf primordia but in the inner region of the SAM. Second, gene

18 expression at the boundary between successive leaf primordia was marked for MND4, but not for

$19 M N D 1$. Finally, MND1 expression in the basal parts of leaf primordia was more apically shifted 20 compared to MND4.

21 These observations suggest that MND4 and MND1 regulate the plastochron and leaf growth 22 by means of their expression in limited but distinct regions of the SAM and leaf primordia.

24 Effect of $m$ ma mutations on the expression level of the three $M N D$ genes

To examine whether $M N D$ genes regulate other $M N D$ genes, we compared the expression 
1 levels of $M N D$ genes among three $m n d$ mutant backgrounds and WT Akashinriki and Mesa, with the

2 former the original cultivar of $m n d 4_{\mathrm{OUM} 169}$ and $m n d 8_{\mathrm{OUM} 165}$ and the latter that of $m n d 1_{\mathrm{OUX} 051}$ (Fig 5).

3 Real-time PCR revealed that the expression of $M N D 8$ was slightly decreased in $m n d 4_{\text {OUM169 }}$ (Fig 5A).

4 This indicates that MND4 positively regulates $M N D 8$ expression. The expression level of $M N D 4$ was

5 slightly upregulated in $m n d 8_{\mathrm{OUM} 165}$ and significantly upregulated in $m n d 1_{\mathrm{OUX} 051}$, suggesting that $M N D 1$

6 negatively regulates $M N D 4$ expression (Fig 5B). The expression level of $M N D 1$ was upregulated in

$7 \quad m n d 8_{\mathrm{OUM} 165}$ and downregulated in $m n d 1_{\mathrm{OUX} 051}$, implying that $M N D 8$ negatively regulates $M N D 1$

8 expression and that $m n d 1_{\text {OUX051 }}$ affects the accumulation of MND1 mRNA (Fig 5C). In addition, we

9 examined the expression of $H v P L A 2$ and $H v P L A 3$ (Fig 5D and 5E). Although HvPLA3 expression was

10 not significantly altered in the three mnd mutants (Fig 5E), HvPLA2 expression was downregulated in

11 the mnd mutants (Fig 5D). This suggests that the three MND genes positively regulate $H v P L A 2$

12 expression.

14 Fig 5. Expression change in $M N D$ and $H v P L A$ in $m n d$ mutant backgrounds. Relative expression

15 levels of MND8 (A), MND4 (B), MND1 (C), HvPLA2 (D), and HvPLA3 (E). ADP-ribosylation factor

16 l-like protein $(A D P)$ was used as the internal control. Double and single asterisks indicate a statistically

17 significant difference compared to the wild type (WT; $t$-test, $\mathrm{P}<0.01$ and 0.05 , respectively).

Accordingly, the expression levels of the three $M N D$ genes in addition to that of $H v P L A 2$ were affected by functional defects in other $M N D$ genes.

\section{Genetic interactions among $M N D$ genes}

To examine the genetic interactions among $M N D$ genes, we generated double mutants

24 between $m n d 8_{\mathrm{OUM} 165}$ and $m n d 4_{\mathrm{OUM} 169}$ as well as $m n d 8_{\mathrm{OUM} 165}$ and $m n d 1_{\mathrm{OUX} 051}$ (Fig 6A and 6B). We 
1 determined the genotypes (Fig 6C and 6D). Among the segregants of the $\mathrm{F}_{3}$ population of $m n d 8_{\mathrm{OUM} 165}$

2 and $m n d 4_{\mathrm{OUM} 169}$, double homozygotic plants for $m n d 8_{\mathrm{OUM} 165}$ and $m n d 4_{\mathrm{OUM} 169}$ produced the largest

3 number of leaves among the nine genotypes (Fig 6A and 6C). Although the difference in leaf number

4 between single $m n d 8_{\text {OUM165 }}$ homozygotic plants and double homozygotic plants was slight, mature

5 double-mutant plants exhibited an enhanced phenotype relative to the $m n d 8_{\text {OUM165 }}$ single mutant (S8

6 Fig), indicating that the $m n d 8_{\text {Oum165 }}$ allele has an additive effect with $m n d 4_{\text {Oum } 169}$. Among the

7 segregants of the $\mathrm{F}_{3}$ population produced from $m n d 8_{\mathrm{OUM} 165}$ and $m n d 1_{\mathrm{OUX} 051}$, an additive effect between

8 the two alleles on leaf number was evident; that is, the $m n d 8_{\mathrm{OUM} 165} m n d 1_{\mathrm{OUX} 051}$ double mutant had the

9 largest number of leaves among the genotypes (Fig 6B and 6D).

11 Fig 6. Effect of mnd double mutations on leaf number. (A, B) Seedling phenotypes of single and

12 double mutants of $m n d 4_{\mathrm{OUM} 169}$ and $m n d 1_{\mathrm{OUX} 051}(\mathrm{~A})$ and $m n d 4_{\mathrm{OUM} 169}$ and $m n d 8_{\mathrm{OUM} 165}(\mathrm{~B})$ at 2 months

13 after germination. Genotypes are indicated below. (C, D) Effect of $m n d 4_{\mathrm{OUM} 169}$ and $m n d 1_{\mathrm{OUX} 051}(\mathrm{C})$ as

14 well as $m n d 4$ oum169 and mnd8 $8_{\text {Oum165 }}$ (D) alleles on leaf number. Arrows and percentages indicate the

15 effect of homozygotic mutations of $m n d s$ on the rate of increase in leaf number.

The mnd alleles had different effects on the increase in leaf number depending on their

18 genotype (Fig 6C and 6D). For example, mnd8 $8_{\mathrm{OUM} 165}$ increased leaf numbers in the WT and

$19 m n d 4_{\text {OUM } 169}$ backgrounds by $94 \%$ and $73 \%$, respectively. Similarly, mnd $4_{\text {OUM } 169}$ increased leaf

20 numbers in the WT and $m n d 8_{\text {OUM } 165}$ backgrounds by $21 \%$ and $8 \%$, respectively (Fig $6 \mathrm{C}$ ). The same

21 tendency was observed for combinations of $m n d 8_{\mathrm{OUM} 165}$ and $m n d 1_{\mathrm{OUX} 051}$ (Fig 6D). Accordingly, the

22 effect of a single mnd allele on the increase in leaf number was diminished by the accumulation of

23 other $m n d$ alleles.

Therefore, $M N D 8$ regulates the plastochron independently of $M N D 4$ and $M N D 1$. In addition,

25 there are genetic or developmental mechanisms that moderately affect the leaf production rate in the

26 short plastochron background. 
2 Relationship between the plastochron and leaf-blade length in the mnd mutant

The shortened plastochron in most plastochron-related mutants is reportedly accompanied by the production of small leaves $[4,6,7,24]$. However, the correlation between leaf production rate and leaf length is unknown. Therefore, the leaf number at 2 months after germination and the length of the second leaf blade of $\mathrm{F}_{3}$ segregants produced from $m n d 8_{\mathrm{OUM} 165}$ and $m n d 4_{\mathrm{OUM} 169}$ and from $m n d 8_{\mathrm{OUM} 165}$ and $m n d l_{\text {OUX051 }}$ were measured (Fig 8). A strong negative correlation between leaf number and leaf-

8 blade length was observed in all $\mathrm{F}_{3}$ segregants for both $m n d 8_{\text {OUM165 }}$ and $m n d 4_{\text {OUM169 }}$ crosses and $9 \quad m n d 8_{\text {OUM } 165}$ and $m n d l_{\text {OUX051 }}$ crosses (Fig 7A and 7B). This correlation was caused by the strength of 10 the allelic effect on leaf production (Fig 7C and 7D). By contrast, no negative correlations were 11 detected among groups of segregants with identical genotypes (S9 Fig). In addition, among various

12 WT and mnd mutant strains, no correlation between leaf number and the maximum length of the leaf 13 blade was observed (S10 Fig, S1 Table).

Fig 7. Relationship between leaf number and leaf-blade length. (A, B) Scatter plots of leaf number at 2 months after germination and the length of the second leaf blade in segregated plants from mnd4 ouM169 $\times m n d 8_{\text {OUM165 }}(\mathrm{A})$ and $m n d 1_{\text {OUX051 }} \times m n d 8_{\text {OUM165 }}(\mathrm{B})$ crossings. The linear regression line and coefficient of determination $\left(\mathrm{R}^{2}\right)$ are indicated.

These observations indicate that the plastochron and leaf-blade length are positively regulated

21 by $M N D$ genes, but they are controlled independently rather than by alterations in the plastochron or leaf length. 
whether the rice homologs of these genes are involved in plastochron regulation is unknown. Therefore, we constructed knockout mutants of rice $M N D 8$ and $M N D 1$ orthologs using CRISPR/Cas9 (S11 Fig.). A phylogenetic analysis indicated that two orthologs of barley MND8 and MND1 are present in rice (S2 Fig; two rice orthologs, OsBE1/Os03g0839200 and $O s B E 2 / \mathrm{Os} 12 \mathrm{~g} 0552600$, for barley $M N D 8$ and two rice orthologs, OsGNAT1/Os06g0650300 and OsGNAT2/Os02g0180400, for barley MND1). We generated single and double mutants of the rice orthologs and calculated the plastochron (Fig 8A-8G).

The number of leaves increased in osgant1, osbe1, osgnat1 osgnat2, and osbe1 osbe 2 compared to the WT, but to a lesser extent compared to pla1-4 (Fig 8G, S12 Fig). This indicates that rice OsBE1 and OsGNAT1 are involved in plastochron regulation, as are their orthologs in barley, but their contribution to the plastochron is of lesser magnitude than that of $M N D$ in barley.

Fig 8. $M N D$ orthologs in rice. (A-F) Seedlings of the WT and rice mutants in $m n d$ orthologs at 10 osgnat2. Arrowheads and arrows indicate the second and fourth leaf blades, respectively. (G) Changes in leaf number during vegetative development. (H-M) Localization of PLA1 (H, K), OsBE1 (I, L), and OsGNAT1 (J, M) mRNAs in longitudinal (H-J) and cross (K-M) sections of the shoot apex of 10-dayold seedlings. Bars: $100 \mu \mathrm{m}$.

In situ hybridization showed that OSBE1 and OSGNAT1 were expressed around SAMs, particularly at the base of young leaf primordia (Fig $8 \mathrm{H}-8 \mathrm{M}$ ), whereas OsBE2 and OsGNAT2 expression was not observed (data not shown). We next compared the expression patterns of PLA1, OsBE1, and OsGNAT1. PLA1 and OsBE1 expression was similar; PLA1, but not OsBE1, was expressed at the base of the P1-related region in the SAM (Fig $8 \mathrm{H}$ and 8I). In addition, OsBE1, but not PLA1, expression was detected in the inner tissue of $\mathrm{P} 3$ and the stem tissue (Fig 8K and 8L). OsGNAT1 expression was strongest at the base of P3 and the boundaries of leaf primordia (Fig 8J and 8M). 
$18 \mathrm{~K}-8 \mathrm{M})$. By contrast, there were differences in the expression patterns of the rice and barley orthologs, although $M N D 4$ and $P L A 1$ expression was similar. Punctate expression of $M N D 1$ was observed in the SAM (Fig 4C), whereas OsGNAT1 expression was detected in the P3 leaf primordium but not in the SAM (Fig 8J and 8M). MND8 did not exhibit a specific expression pattern (Fig 4B), but OsBE1 was expressed around the shoot apex (Fig 8I and 8L).

These results indicate functional conservation between the barley and rice orthologous genes (MND8 versus $O s B E 1$ and $M N D 1$ versus $O s G N A T 1)$.

\section{Discussion}

10 Three $M N D$ genes regulate the plastochron via similar developmental pathways, but have

\section{1 unrelated functions and genetic pathways}

Our results indicate that the many-noded phenotype of mnd mutants results from the rapid

13 production of leaf primordia, which is caused by loss-of function of three independent loci, $M N D 4$,

$14 M N D 8$, and MND1. Although the magnitude of the plastochron reduction differed among the mutant

15 alleles, the overall phenotypes of all mnd mutants during vegetative development were similar. In

16 addition, the panicle-development phenotypes were comparable. In the normal panicle of barley, a

17 non-branched single axis of the panicle is produced, but diverged and multiple panicles were observed

18 in $m n d 8_{\text {OUM165 }}$ and $m n d 1_{\text {OUX051 }}\left(\mathrm{S} 11 \mathrm{Fig}\right.$ ). A panicle abnormality was also recognized in $m n d 4_{\mathrm{OUM} 169}$,

19 which exhibited the weakest vegetative-development phenotype among the mnd mutants. Therefore,

20 common abnormalities were exhibited during vegetative and reproductive development, indicating

21 that the three $M N D$ genes have similar roles in barley development.

Despite their similar biological functions, the three $M N D$ genes encode unrelated proteins.

23 MND4 encodes a CYP78A monooxygenase whose substrates are unknown [29]. Although CYP78A

24 genes are important for development in several species [29, 37-41], the synthetic or metabolic

25 pathways in which CYP78A is involved are unknown. MND1 encodes an N-acetyltransferase-like 
1 protein and is the closest homolog of GW6a in rice [36]. Because GW6a exhibits histone H4

2 acetyltransferase activity, $M N D 1$ also likely regulates the transcription of downstream genes by

3 acetylating histone H4. Furthermore, MND8 is an ortholog of maize BIGE1, a transporter implicated

4 in the secretion of an unidentified small molecule [24]. Accordingly, it is assumed that MND4, MND1,

5 and MND8 are involved in the synthesis or metabolism of unknown factors, transcriptional regulation

6 of downstream genes, and transportation of unidentified molecules, respectively. Although a close

7 relationship between the CYP78A pathway and BIGE1 has been proposed [24], there is no direct

8 evidence that BIGE1 is associated with the transportation of CYP78A-related molecules so far. In fact,

9 although we did not investigate the relationship between MND4 and MND1, our genetic analysis

10 indicates that MND4 and MND1 regulate the plastochron independently of MND8. Accordingly, at

11 least two different genetic pathways regulate the plastochron in barley. This is also the case for

12 plastochron regulation by three PLA genes in rice. The pla1, pla2, and pla3 mutants have a short

13 plastochron and a small leaf size, and conversion of the primary rachis into a shoot occurs in all three,

14 but it has been proposed that PLA1, PLA2, and PLA3 regulate the plastochron independently [7, 9].

15 On the other hand, Arabidopsis AMP1 and CYP78A5/7, which are orthologs of PLA3 and PLA1,

16 respectively, act on a common downstream process [42].

17 Therefore, the developmental program controlling leaf initiation, leaf growth, and panicle

18 development in rice and barley is regulated by multiple and independent genetic pathways involving

$19 \quad P L A$ and $M N D$ genes.

\section{$21 \quad$ Interactions of $M N D$ genes}

At least two independent genetic pathways regulate the plastochron, and complex genetic

23 interactions were suggested by the expression analysis. In short, $M N D 8$ negatively regulates $M N D 1$,

24 MND1 negatively regulates $M N D 4$, and $M N D 4$ positively regulates $M N D 8$. It was also noted that

$25 M N D 4$ expression was slightly upregulated, but not significantly, in mnd8. Such a regulatory 
1 relationship between CYP78A and a MND8-related transporter has also been reported in maize; i.e.,

2 the expression of some CYP78A family genes was upregulated in the bigel mutant background [24].

3 In maize, $B I G E 1$ is required for feedback regulation of CYP78A family genes. If this is also the case

4 in barley, the upregulation of MND4 and MND1 might have been the result of a deficiency in feedback

5 regulation caused by the loss of $M N D 8$ function. By contrast, overexpression of rice $G W 6 a$, an

6 ortholog of $M N D 1$, and the mndl.a mutation affected the expression levels of thousands of genes in

7 rice and barley, respectively $[28,36]$. Because $G W 6 a$ is predicted to be a transcriptional regulator that

8 modulates chromatin status, a change in MND4 expression in mnd1 could be a direct or indirect effect

9 of loss of histone acetyltransferase activity by MND1. Although MND4 and MND8 do not directly

10 affect gene transcription, they modulate that of other genes by influencing downstream events. In

11 addition to the three $M N D$ genes, expression of HvPLA2 was downregulated in the three mnd mutants.

12 This indicates that $H v P L A 2$ is involved in plastochron regulation downstream of the three $M N D$ genes.

13 Phenotypic analysis of double mutants revealed that the effect of $M N D$ genes on plastochron

14 regulation was dependent on the number of mnd mutant alleles present. Although it is unknown

15 whether this phenomenon is a result of genetic interactions among the $M N D$ genes or a developmental

16 restriction of plastochron regulation at the SAM, complex genetic and developmental interactions are

17 implicated in the regulation of the plastochron.

\section{$19 M N D$ genes function in leaf production and growth}

In shortened-plastochron mutants, rapid leaf production is accompanied by small leaves [4,

$216,7,24]$. In plal and pla2 mutants in rice, a model of the effect of leaf production on leaf size was

22 proposed. According to the model, rapid leaf production by pla mutants is not the result of the loss of

23 PLA function in the SAM, but an indirect effect of accelerated leaf maturation in leaf primordia [7].

24 The model was based on the observation that PLA genes were expressed in leaf primordia but not in 
1 the SAM, although the mechanism by which the change in leaf-primordia maturation affects leaf

2 production is unknown.

Our barley analysis supports the above notion. The relative developmental stage and cell-

division activity of successive leaf primordia were maintained or increased in the mnd mutants.

Therefore, leaf production and leaf-primordia maturation were accelerated, as for pla mutants in rice.

Accordingly, $M N D$ genes maintain the leaf-maturation schedule. However, if the leaf production rate is affected only by leaf maturation, as suggested by the rice model, the correlation between leaf number and leaf-blade length should be solid. However, we showed that leaf number and leaf-blade length were not always correlated in plants of identical genotype, implying that the plastochron and leaf size are differentially regulated. In fact, expression of MND4 and MND1 was observed both in the SAM

11 and leaf primordia. $M N D$ expression in the SAM may be required for the suppression of leaf initiation

12 independently of expression in the leaf primordia, which is necessary for the suppression of leaf

13 maturation. This is supported by the fact that enhanced expression of the maize PLA1 ortholog in leaf

14 primordia affected leaf size but not leaf number [41], whereas overexpression of PLA1 via the

15 introduction of an increased gene copies resulted in a prolonged plastochron and an increased leaf size

16 [43]. Furthermore, maize PLA1 genes control the duration of cell division in the leaf primordia [41],

17 which is consistent with the rapid leaf maturation observed in the mnd4 mutant in this study.

The mechanisms by which $M N D$ genes regulate leaf initiation in the SAM and leaf growth in

19 the leaf primordia are unknown. Auxin may be associated with control of the duration of cell-division 20 activity by maize PLA1 [41]. It is also probable that auxin triggers leaf initiation via $M N D$-mediated 21 regulation, because the local auxin concentration is important for leaf initiation in the SAM [1, 44]. It 22 is possible that the limited $M N D 1$ and $M N D 4$ expression domain in the SAM is important for the auxin 23 flow or concentration required for proper leaf initiation. Analysis of auxin dynamics in the mutant 24 SAM may provide insight into the role of auxin in the temporal regulation of leaf initiation by $M N D$ s. 


\section{Conservation and diversity of genetic pathways in rice and barley}

Although several genetic factors regulating the plastochron have been identified in rice, maize,

3 Arabidopsis, and other species, our understanding of their functional conservation among plant species

4 is inadequate. We characterized mnd mutants in barley and identified the responsible genes. It was somewhat surprising that two of the three $M N D$ genes were not homologs of three PLA genes in rice. At least five genes are involved in developmental pathways underpinning plastochron regulation in grasses. Moreover, three of the five orthologs perform similar functions in rice and barley. However, there was a considerable difference in the magnitude of their effects between the two species. For example, loss-of-function of $M N D 1$ and $M N D 8$ markedly shortened the plastochron in barley, but that

10 of the rice orthologs $O s G N A T 1$ and $O S B E 1$ resulted in a slight effect, even for double loss-of-function

11 of closely related paralogs. This might have been caused by differences in genetic redundancy and

12 functional diversification of gene families between the two species. Namely, other homologs in

13 different clades compensate for the function of plastochron regulation in rice. In fact, the functional

14 ortholog of MND4 in rice is PLA1, but it is not the closest homolog among the CYP78A members

15 [29]. It is predicted that $0 s 09 g 0528700$ is a phylogenetic ortholog of MND4 in rice, which is

16 specifically expressed in roots and the embryo (http://ricexpro.dna.affrc.go.jp), unlike PLA1. In terms

17 of the functions of $M N D 8$-related MATE transporter-family genes, BIGE1 in maize regulates both the

18 leaf initiation rate and embryo size [24]. However, mnd8 in barley did not exhibit a phenotype change

19 in terms of embryo size (S14 Fig). In addition, $O s B E 1$, a rice ortholog of $M N D 8$, exhibited specific

20 expression around the shoot apex, unlike MND8. Accordingly, the phenotypic effect and expression

21 pattern of the closest homologs of $M N D$ genes differ among grass species.

Our understanding about a conserved function of plastochron-related genes among grass species is still insufficient. Identifications of $H v P L A 2$ and $H v P L A 3$ mutants in barley and comparative analyses with their rice counterparts would advance an understanding of the conservation and diversity of plastochron-related genes. 


\section{Materials and Methods}

\section{$2 \quad$ Plant materials and growth conditions}

The barley mnd mutant and WT strains used in this study were listed in Table 1. Mutant and wild-type seeds were grown in soil under natural conditions, and the plants were sampled and their phenotypes evaluated at predetermined timepoints. For the double mutant analysis, the genotypes of the $\mathrm{F}_{3}$ plants were identified using PCR-based genotyping.

The plal-4 mutant and WT rice plants were grown on soil or MS medium containing 3\% sucrose and $1 \%$ agar at $28^{\circ} \mathrm{C}$ under continuous light. Transgenic plants were grown in a biohazard greenhouse

9 with temperatures of $30^{\circ} \mathrm{C}$ in the daytime and $25^{\circ} \mathrm{C}$ at night.

\section{Histological and morphological analysis}

Samples of the mutant and WT plants were fixed with FAA (formaldehyde:glacial acetic

13 acid:50\% ethanol, 2:1:17) for $24 \mathrm{~h}$ at $4{ }^{\circ} \mathrm{C}$ for histological analysis, or with PFA (4\% [w/v]

14 paraformaldehyde and $1 \%$ Triton $\mathrm{X}$ in $0.1 \mathrm{M}$ sodium phosphate buffer) for $48 \mathrm{~h}$ at $4{ }^{\circ} \mathrm{C}$ for in situ

15 hybridization. They were then dehydrated in a graded ethanol series, after which the ethanol was

16 substituted with 1-butanol, and the samples were embedded in Paraplast ${ }^{\circledR}$ Plus (McCormick

17 Scientific). The samples were sectioned at a thickness of $8 \mu \mathrm{m}$ using a rotary microtome. The sections

18 were stained with hematoxylin for histological analysis. After staining, the sections were mounted with

19 Poly-Mount ${ }^{\circledR}$ (Polysciences, Inc.) and observed under a light microscope.

20 For scanning electron microscopy, plant materials were fixed in PFA for $24 \mathrm{~h}$ and dehydrated in

21 an ascending ethanol series, which was then gradually replaced with 3-methyl-butyl-acetate. Samples

22 were critical-point dried, sputter-coated with platinum, and observed under a scanning electron

23 microscope (S-4800, Hitachi) at an accelerating voltage of $10 \mathrm{kV}$. 
Paraffin sections were prepared as described above. For digoxigenin-labeled antisense RNA

2 probes, those for histone $H 4$ (HvH4: HORVU5Hr1G086620), MND4, MND8, and MND1 in barley

3 and $O S B E 1$ and $O s G N A T 1$ in rice were prepared using cDNAs and specific primers (S2 Table). The

$4 \quad$ PLA1 probes were prepared as described previously [5]. In situ hybridization and immunological

5 detection using alkaline phosphatase were performed according to the methods of Kouchi and Hata $6 \quad[45]$.

8 Identification of $M N D$ genes and $P L A 2$ and $P L A 3$ orthologs in barley

The nucleotide sequences of MND4, MND8, MND1, HvPLA2, and HvPLA3 in the $m n d \mathrm{~s}$ and

10 WT were determined using sequence information from the IPK Barley Blast Server

11 (https://webblast.ipk-gatersleben.de/barley_ibsc/) and Phytozome (https://phytozome.jgi.doe.gov/).

For phylogenic analyses, the amino-acid sequences of MND4, MND8, and MND1 homologs in

13 various plant species were obtained from the Phytozome database. The amino-acid alignment was

14 carried out using GENETYX software (Genetyx), and the phylogenic tree was constructed based on

15 the neighbor-joining method with 1,000-replicate bootstrapping using Molecular Evolutionary

16 Genetics Analysis (MEGA X; [46]).

\section{Quantitative real-time PCR}

RNA was extracted from the shoot apices of barley seedlings at 2 WAG using TRIzol®

20 reagent (Invitrogen). The extracted RNA was treated with Recombinant DNase I (TaKaRa), and cDNA

21 was synthesized using the High-Capacity cDNA Reverse Transcription Kit (Life Technologies).

22 Quantitative real-time PCR was performed with the StepOne ${ }^{\mathrm{TM}}$ Real-Time PCR System (Life

23 Technologies) using TaqMan Fast Universal PCR Master Mix and FAM-labeled TaqMan probes for

24 each gene. ADP-ribosylation factor 1-like protein $(A D P)$ was used as the internal standard [47]. In all

25 experiments, we analyzed three technical and three biological replicates. The primers and TaqMan 
1 probes for $M N D 1, M N D 4, M N D 8, A D P, H v P L A 2$, and $H v P L A$ are listed in S3 Table.

3 Generation of knockout alleles of rice $M N D$ orthologs using the CRISPR/Cas9 system

The CRISPR/Cas9 system was used to generate knockout alleles for OsBE1, OsBE2,

OsGNAT1, and OsGNAT2, which are orthologs of MND1 and MND8 in rice. The target sites were selected using the CRISPR-P program (http://cbi.hzau.edu.cn/crispr/) [48] (S11 Fig). The single-guide RNA (sgRNA) cloning vector (pZK_gRNA) and all-in-one binary vector 8 (pZH_OsU6gRNA_MMCas9) harboring sgRNA, Cas9, and NPTII were provided by Masaki Endo 9 [49]. The pZH_OsU6gRNA_MMCas9 vector including target-guide RNA for MND orthologs was 10 constructed as described previously [49].

11 The constructs were introduced into Agrobacterium tumefaciens strain EHA105 and transformed 12 into cultivar Taichung-65 (T-65) calli via Agrobacterium-mediated transformation. Mutations and 13 transgenes in each transformant were confirmed by sequencing and PCR-based detection (S11 Fig).

Data availability

The GenBank accession numbers for the genes in the text are HvPLA2, LC593235; HvPLA3, LC593236; MND4, LC593237; MND1, LC593238; MND8, LC593239; OsBE1, LC593240; OsBE2, LC593241; OsGNAT1, LC593242; and OsGNAT2, LC593243.

\section{Acknowledgments}

The barley resources were provided by the National Bioresource Project-Barley, Okayama

22 University, Japan; USDA, Aberdeen, Idaho; Nordic Genetic Resource Center, Sweden; and Tochigi

23 Agricultural Experiment Station, Japan. This work was supported in part by the Ministry of Education,

24 Culture, Sports, Science and Technology (MEXT) as part of a Joint Research Program implemented

25 at the Institute of Plant Science and Resources, Okayama University, Japan. 


\section{References}

3 1. Lee B, Yu S, Jackson D. Control of plant architecture: The role of phyllotaxy and plastochron. J Plant Biol. 2009;52(4):277-82. Available from: http://ink.springer.com/10.1007/s12374-0099034-x

2. Wang B, Smith SM, Li J. Genetic regulation of shoot architecture. Annu Rev Plant Biol. 2018;69(1):437-68. Available from: http://www.annualreviews.org/doi/10.1146/annurevarplant-042817-040422

9 3. Itoh J, Hibara K, Kojima M, Sakakibara H, Nagato Y. Rice DECUSSATE controls phyllotaxy 10 by affecting the cytokinin signaling pathway. Plant J. 2012;72(6):869-81. Available from: http://doi.wiley.com/10.1111/j.1365-313x.2012.05123.x

4. Itoh J-I, Hasegawa A, Kitano H, Nagato Y. A recessive heterochronic mutation, plastochron1, shortens the plastochron and elongates the vegetative phase in rice. Plant Cell. 1998;10(9):151121. Available from: http://www.plantcell.org/lookup/doi/10.1105/tpc.10.9.1511

5. Miyoshi K, Ahn B-O, Kawakatsu T, Ito Y, Itoh J-I, Nagato Y, et al. PLASTOCHRON1, a timekeeper of leaf initiation in rice, encodes cytochrome P450. Proc Natl Acad Sci U S A. 2004;101(3):875-80. Available from: http://www.pnas.org/cgi/doi/10.1073/pnas.2636936100

6. Wang JW, Schwab R, Czech B, Mica E, Weigel D. Dual effects of miR156-targeted SPL genes and CYP78A5/KLUH on plastochron length and organ size in Arabidopsis thaliana. Plant Cell.

7. Kawakatsu T, Itoh J-I, Miyoshi K, Kurata N, Alvarez N, Veit B, et al. PLASTOCHRON2 regulates leaf initiation and maturation in rice. Plant Cell. 2006;18(3):612-25. Available from: http://www.plantcell.org/lookup/doi/10.1105/tpc.105.037622

8. Veit B, Briggs SP, Schmidt RJ, Yanofsky MF, Hake S. Regulation of leaf initiation by the terminal ear 1 gene of maize. Nature. 1998;393(6681):166-8. Available from: http://www.nature.com/articles/30239 
1 9. Kawakatsu T, Taramino G, Itoh J-I, Allen J, Sato Y, Hong S-K, et al.

PLASTOCHRON3/GOLIATH encodes a glutamate carboxypeptidase required for proper development in rice. Plant J. 2009;58(6):1028-40. Available from: http://doi.wiley.com/10.1111/j.1365-313X.2009.03841.x

10. Helliwell CA, Chin-Atkins AN, Wilson IW, Chapple R, Dennis ES, Chaudhury A. The Arabidopsis AMP1 gene encodes a putative glutamate carboxypeptidase. Plant Cell. 2001;13(9):2115-25. Available from: http://www.plantcell.org/lookup/doi/10.1105/TPC.010146

11. Suzuki M, Latshaw S, Sato Y, Settles AM, Koch KE, Hannah LC, et al. The maize viviparous8 locus, encoding a putative ALTERED MERISTEM PROGRAM1-like peptidase, regulates

12. Rhoades MW, Reinhart BJ, Lim LP, Burge CB, Bartel B, Bartel DP. Prediction of plant microRNA targets. Cell. 2002;110(4):513-20. Available from: https://linkinghub.elsevier.com/retrieve/pii/S0092867402008632

13. Yamasaki K, Kigawa T, Inoue M, Tateno M, Yamasaki T, Yabuki T, et al. A novel zinc-binding motif revealed by solution structures of DNA-binding domains of Arabidopsis SBP-family transcription factors. J Mol Biol. 2004;337(1):49-63. Available from: https://linkinghub.elsevier.com/retrieve/pii/S0022283604000610

14. Xie K, Wu C, Xiong L. Genomic organization, differential expression, and interaction of SQUAMOSA promoter-binding-like transcription factors and microRNA156 in rice. Plant Physiol. 2006;142(1):280-93. Available from: http://www.plantphysiol.org/lookup/doi/10.1104/pp.106.084475

15. Xie K, Shen J, Hou X, Yao J, Li X, Xiao J, et al. Gradual increase of miR156 regulates temporal expression changes of numerous genes during leaf development in rice. Plant Physiol. 2012;158(3):1382-94. Available from: 
http://www.plantphysiol.org/lookup/doi/10.1104/pp.111.190488

16. Schwarz S, Grande A V., Bujdoso N, Saedler H, Huijser P. The microRNA regulated SBP-box genes SPL9 and SPL15 control shoot maturation in Arabidopsis. Plant Mol Biol. 2008;67(12):183-95. Available from: http://link.springer.com/10.1007/s11103-008-9310-z

17. Chuck G, Cigan AM, Saeteurn K, Hake S. The heterochronic maize mutant Corngrass1 results from overexpression of a tandem microRNA. Nat Genet. 2007;39(4):544-9. Available from: http://www.nature.com/articles/ng2001

18. Chuck G, Whipple C, Jackson D, Hake S. The maize SBP-box transcription factor encoded by

19. Chuck GS, Brown PJ, Meeley R, Hake S. Maize SBP-box transcription factors unbranched2 and

23. Wang L, Sun S, Jin J, Fu D, Yang X, Weng X, et al. Coordinated regulation of vegetative and unbranched 3 affect yield traits by regulating the rate of lateral primordia initiation. Proc Natl Acad Sci U S A. 2014;111(52):18775-80. Available from: http://www.pnas.org/lookup/doi/10.1073/pnas.1407401112

20. Jiao Y, Wang Y, Xue D, Wang J, Yan M, Liu G, et al. Regulation of OsSPL14 by OsmiR156 defines ideal plant architecture in rice. Nat Genet. 2010;42(6):541-4. Available from: http://www.nature.com/articles/ng.591

21. Miura K, Ikeda M, Matsubara A, Song X-J, Ito M, Asano K, et al. OsSPL14 promotes panicle branching and higher grain productivity in rice. Nat Genet. 2010;42(6):545-9. Available from: http://www.nature.com/articles/ng.592

22. Luo L, Li W, Miura K, Ashikari M, Kyozuka J. Control of tiller growth of rice by OsSPL14 and strigolactones, which work in two independent pathways. Plant Cell Physiol. 2012;53(10):1793801. Available from: https://academic.oup.com/pcp/article-lookup/doi/10.1093/pcp/pcs122 reproductive branching in rice. Proc Natl Acad Sci U S A. 2015;112(50):15504-9. Available 
from: http://www.pnas.org/lookup/doi/10.1073/pnas.1521949112

24. Suzuki M, Sato Y, Wu S, Kang B-H, McCarty DR. Conserved functions of the MATE transporter BIG EMBRYO1 in regulation of lateral organ size and initiation rate. Plant Cell. 2015;27(8):2288-300. Available from: http://www.plantcell.org/lookup/doi/10.1105/tpc.15.00290

25. Druka A, Franckowiak J, Lundqvist U, Bonar N, Alexander J, Houston K, et al. Genetic dissection of barley morphology and development. Plant Physiol. 2011;155(2):617-27.

26. Mascher M, Gundlach H, Himmelbach A, Beier S, Twardziok SO, Wicker T, et al. A chromosome conformation capture ordered sequence of the barley genome. Nature.

27. Harlan H V., Pope MN. MANY-NODED DWARF BARLEY. J Hered. 1922;13(6):269-73. Available from: https://academic.oup.com/jhered/article/766940/MANY-NODED

28. Walla A, Wilma van Esse G, Kirschner GK, Guo G, Brünje A, Finkemeier I, et al. An acyl-CoA

29. Mascher M, Jost M, Kuon J-E, Himmelbach A, Aßfalg A, Beier S, et al. Mapping-by$\mathrm{N}$-acyltransferase regulates meristem phase change and plant architecture in barley. Plant Physiol. 2020;183(3):1088-109. Available from: http://www.plantphysiol.org/lookup/doi/10.1104/pp.20.00087 sequencing accelerates forward genetics in barley. Genome Biol. 2014;15(6):R78. Available from: http:/genomebiology.biomedcentral.com/articles/10.1186/gb-2014-15-6-r78

30. McMaster GS. Phytomers, phyllochrons, phenology and temperate cereal development. J Agric Sci. $2005 ; 143(2-3): 137-50$. Available from: https://www.cambridge.org/core/product/identifier/S0021859605005083/type/journal_article

31. Sato K, Nankaku N, Takeda K. A high-density transcript linkage map of barley derived from a single population. Heredity. 2009;103(2):110-7. Available from: http://www.nature.com/articles/hdy200957 
32. Varshney RK, Marcel TC, Ramsay L, Russell J, Röder MS, Stein N, et al. A high density barley microsatellite consensus map with 775 SSR loci. Theor Appl Genet. 2007;114(6):1091-103. Available from: http://link.springer.com/10.1007/s00122-007-0503-7

33. Lehman A, Black R, Ecker JR. HOOKLESS1, an ethylene response gene, is required for differential cell elongation in the Arabidopsis hypocotyl. Cell. 1996;85(2):183-94. Available from: https://linkinghub.elsevier.com/retrieve/pii/S0092867400810958

34. Li H, Johnson P, Stepanova A, Alonso JM, Ecker JR. Convergence of signaling pathways in the control of differential cell growth in Arabidopsis. Dev Cell. 2004;7(2):193-204. Available from: https://linkinghub.elsevier.com/retrieve/pii/S1534580704002175

35. Chang KN, Zhong S, Weirauch MT, Hon G, Pelizzola M, Li H, et al. Temporal transcriptional response to ethylene gas drives growth hormone cross-regulation in Arabidopsis. Elife. 2013;2 :e00675. Available from: https://elifesciences.org/articles/00675

36. Song XJ, Kuroha T, Ayano M, Furuta T, Nagai K, Komeda N, et al. Rare allele of a previously unidentified histone $\mathrm{H} 4$ acetyltransferase enhances grain weight, yield, and plant biomass in rice. Proc Natl Acad Sci U S A. 2015;112(1):76-81. Available from:

37. Anastasiou E, Kenz S, Gerstung M, MacLean D, Timmer J, Fleck C, et al. Control of plant http://www.pnas.org/lookup/doi/10.1073/pnas.1421127112 organ size by KLUH/CYP78A5-dependent intercellular signaling. Dev Cell. 2007;13(6):843-56. Available from: https://linkinghub.elsevier.com/retrieve/pii/S1534580707003796

38. Chakrabarti M, Zhang N, Sauvage C, Munos S, Blanca J, Canizares J, et al. A cytochrome P450 regulates a domestication trait in cultivated tomato. Proc Natl Acad Sci U S A. 2013;110(42):17125-30. Available from: http://www.pnas.org/cgi/doi/10.1073/pnas.1307313110

39. Ma M, Wang Q, Li Z, Cheng H, Li Z, Liu X, et al. Expression of TaCYP78A3, a gene encoding cytochrome P450 CYP78A3 protein in wheat ( Triticum aestivum L.), affects seed size. Plant J. 2015;83(2):312-25. Available from: http://doi.wiley.com/10.1111/tpj.12896 
40. Ma M, Zhao H, Li Z, Hu S, Song W, Liu X. Retracted: TaCYP78A5 regulates seed size in wheat (Triticum aestivum). J Exp Bot. 2016;67(5):1397-410. Available from: https://academic.oup.com/jxb/article/67/5/1397/2885115

41. Sun X, Cahill J, Van Hautegem T, Feys K, Whipple C, Novák O, et al. Altered expression of maize PLASTOCHRON1 enhances biomass and seed yield by extending cell division duration. Nat Commun. 2017;8(1):14752. Available from: http://www.nature.com/articles/ncomms14752

42. Poretska O, Yang S, Pitorre D, Poppenberger B, Sieberer T. AMP1 and CYP78A5/7 act through a common pathway to govern cell fate maintenance in Arabidopsis thaliana. PLoS Genet.

43. Hibara K, Isono M, Mimura M, Sentoku N, Kojima M, Sakakibara H, et al. Jasmonate regulates juvenile-to-adult phase transition in rice. Development. 2016;143(18):3407-16. Available from: http://dev.biologists.org/lookup/doi/10.1242/dev.138602

44. Reinhardt D, Pesce E-R, Stieger P, Mandel T, Baltensperger K, Bennett M, et al. Regulation of

45. Kouchi $\mathrm{H}$, Hata $\mathrm{S}$. Isolation and characterization of novel nodulin cDNAs representing genes

46. Kumar S, Stecher G, Li M, Knyaz C, Tamura K. MEGA X: Molecular evolutionary genetics analysis across computing platforms. Mol Biol Evol. 2018;35(6):1547-9. Available from: https://academic.oup.com/mbe/article/35/6/1547/4990887

47. Ferdous J, Li Y, Reid N, Langridge P, Shi B-J, Tricker PJ. Identification of reference genes for quantitative expression analysis of microRNAs and mRNAs in barley under various stress conditions. PLoS One. 2015;10(3):e0118503. Available from: https://dx.plos.org/10.1371/journal.pone.0118503

48. Lei Y, Lu L, Liu H-Y, Li S, Xing F, Chen L-L. CRISPR-P: A web tool for synthetic single- 
guide RNA design of CRISPR-system in plants. Mol Plant. 2014;7(9):1494-6. Available from: https://linkinghub.elsevier.com/retrieve/pii/S1674205214609527

49. Mikami M, Toki S, Endo M. Comparison of CRISPR/Cas9 expression constructs for efficient targeted mutagenesis in rice. Plant Mol Biol. 2015 19;88(6):561-72.

\section{Supporting Information}

S1 Fig. Changes in the leaf primordia of mnd mutants at 1-2 weeks after germination. Inner

structure of the wild-type and mnd mutants at 1 week $(\mathrm{A}-\mathrm{D})$ and 2 weeks $(\mathrm{E}-\mathrm{H})$ after germination. (A,

9 E) Akashinriki, $(\mathrm{B}, \mathrm{F}) m n d 8_{\text {OUM165 }},(\mathrm{C}, \mathrm{G}) m n d 4_{\text {OUM } 169}$, and $(\mathrm{D}, \mathrm{H}) m n d 1_{\text {OUX051. }} \mathrm{xL}$ indicates the $\mathrm{x}^{\text {th }}$

10 leaf and Px indicates the order of leaf emergence from the shoot apical meristem. col, coleoptile. Bars:

$11200 \mu \mathrm{m}$

12 S2 Fig. Phylogenetic tree of MND proteins. Phylogenetic tree of MND proteins from several

13 angiosperms. (A) MND4, (B) MND8, and (C) MND1. Numbers above the branches are bootstrap

14 values from 1,000 replicates. At, Arabidopsis thaliana; Zm, Zea mays; Os, Oryza sativa; Hv, Hordeum

15 vulgare. Red and blue underlining indicates MNDs in barley and orthologs in rice, respectively.

16 S3 Fig. Amino-acid alignment of MND4 and its homologs. Alignment of MND4 and its homologous

17 proteins in several angiosperms used in S2 Fig. The effect of each mnd mutation is indicated in red.

18 Black and gray, $100 \%$ and more than 50\% identical amino acids, respectively. At, Arabidopsis

19 thaliana; Zm, Zea mays; Os, Oryza sativa; Hv, Hordeum vulgare

20 S4 Fig. Amino-acid alignment of MND8 and its homologs. Alignment of MND8 and its homologous

21 proteins in several angiosperms used in S2 Fig. The effect of each mnd mutation is indicated in red.

22 Black and gray, $100 \%$ and more than 50\% identical amino acids, respectively. At, Arabidopsis

23 thaliana; Zm, Zea mays; Os, Oryza sativa; Hv, Hordeum vulgare.

24 S5 Fig. Amino-acid alignment of MND1 and its homologs. Alignment of MND1 and its homologs

25 in the angiosperms used in S2 Fig. The effect of each $m n d$ mutation is indicated in red. Black and gray, 
$1 \quad 100 \%$ and more than 50\% identical amino acids, respectively. At, Arabidopsis thaliana; Zm, Zea mays;

Os, Oryza sativa; Hv, Hordeum vulgare.

S6 Fig. Genomic structure of $H v P L A 2$ and $H v P L A 3$. Boxes indicate exons. DNA polymorphisms between Akashinriki and OUX051 in the HvPLA3 genomic structure are indicated by arrows.

S7 Fig. Amino-acid alignment of HvPLA3 and its homologs. Alignment of HvPLA3 and its homologs in several angiosperms. The effects of mutations in OUX051 are indicated in red. Black and gray, $100 \%$ and more than 50\% identical amino acids, respectively. LOC, Oryza sativa; GRMZM, Zea mays; Solyc, Solanum lycopersicum; Medtr, Medicago truncatula; AT, Arabidopsis thaliana.

S8 Fig. Mature plant phenotypes of mnd double mutants. (A) Segregated plants of the $F_{3}$ population derived from the $\mathrm{F}_{2}$ seeds of mnd4 ouM169 $\times$ mnd8 $8_{\text {OUM165 }}$ crossings. (B) Segregated plants of the $\mathrm{F}_{3}$

11 population derived from the $\mathrm{F}_{2}$ seeds of $m n d 1_{\text {OUX } 051} \times m n d 8_{\text {OUM165 }}$ crossings. The genotypes of the 12 plants are indicated.

13 S9 Fig. Relationship between leaf number and leaf-blade length among plants of the same

14 genotype. (A, B) Scatter plots of leaf number at 2 months after germination and the length of the 15 second leaf blade with the same genotype from $m n d 4$ oum169 $\times m n d 8_{\text {OUM165 }}$ (A), and $m n d 1_{\text {OUX051 }} \times$ 16 mnd8 $8_{\text {OUM } 165}$ (B) crossings. The linear regression line and the coefficient of determination $\left(\mathrm{R}^{2}\right)$ are 17 indicated.

18 S10 Fig. Relationship between leaf number and maximum leaf-blade length. Scatter plot of leaf 19 number at 100 days after germination and the maximum length of the leaf blade. Average values of 20 the traits of five plants were used. The linear regression line and coefficient of determination $\left(\mathrm{R}^{2}\right)$ are 21 indicated.

S11 Fig. CRISPR/Cas9-mediated mutagenesis of rice MND orthologs. (A-D) Genomic structures and target sites of rice MND orthologs. (A) OsGNAT1, (B) OsGNAT2, (D) $O s B E 2$.

24 Boxes indicate exons. Arrows indicate target sites (protospacer adjacent motif [PAM] sequences [red characters] and guide sequences [blue characters]) and directions starting from each PAM sequence. 
1 S12 Fig. Leaf number of wild-type (T-65) plants and CRISPR/Cas9-induced mutants at 10 days

2 after sowing. Data are presented as the means \pm SDs $(n \geq 5)$.

3 S13 Fig. Panicle phenotypes of mnd mutants. Arrows indicate elongated bracts or ectopic shoot-like

4 structures; arrowheads indicate branched panicles.

$5 \quad$ S14 Fig. Seed phenotypes of mnd mutants. (A) Akashinriki, (B) mnd4 oum169, (C) mnd $8_{\text {OUM165, and }}$

6 (D) mnd1 $1_{\text {OUX051. }}$ Bars: $2 \mathrm{~mm}$.

$7 \quad$ S1 Table. Leaf number and leaf size in the wild type and mnd mutants.

$8 \quad$ S2 Table. Primers used to produce in situ hybridization probes.

$9 \quad$ S3 Table. Primers and TaqMan probes used for real-time PCR. 
Fig 8
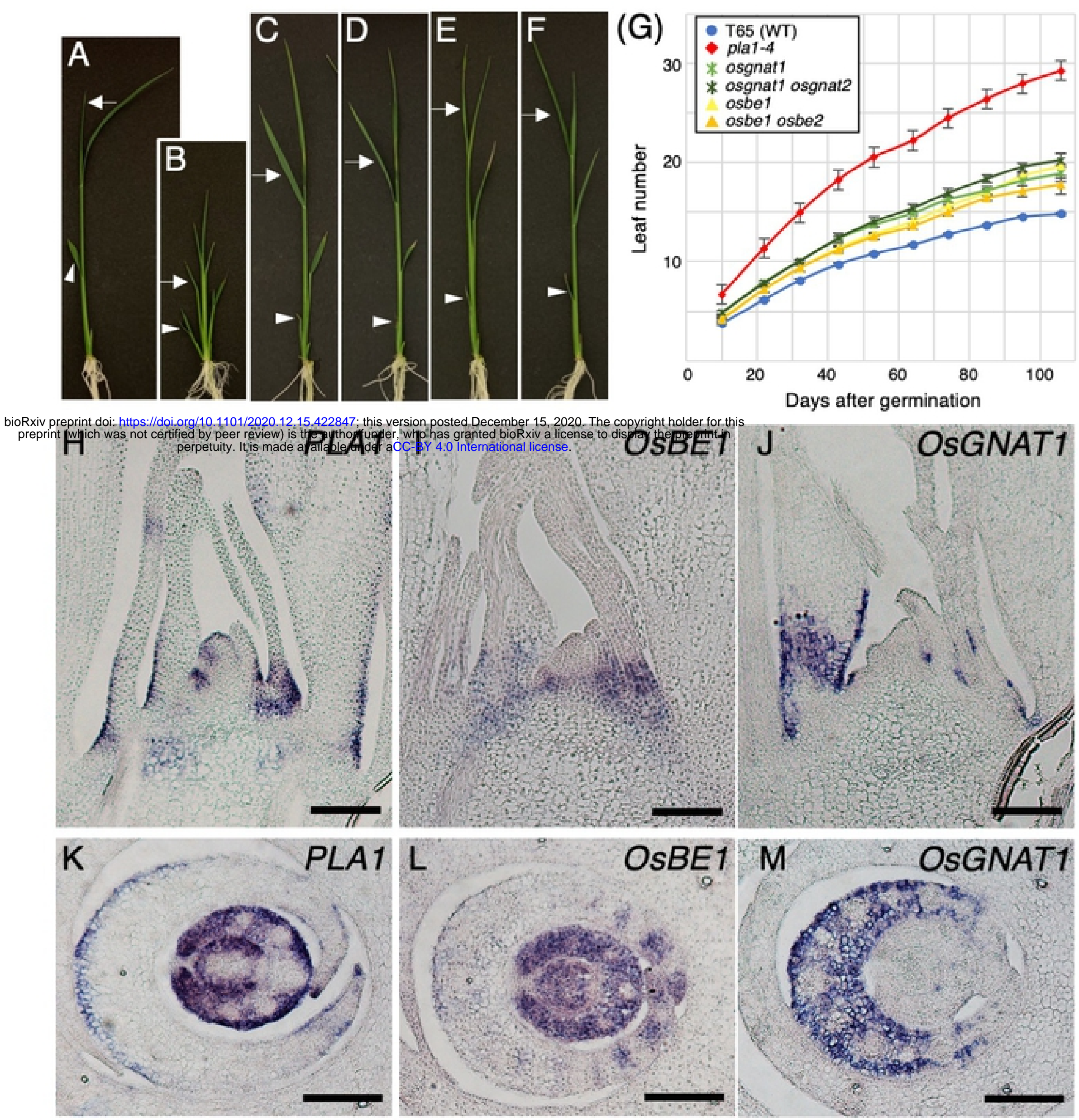

Fig 8. MND orthologs in rice. (A-F) Seedlings of the WT and rice mutants in mnd orthologs at 10 days after germination. (A) T-65, (B) pla1-4, (C) osbe1, (D) osbe1 osbe2, (E) osgnat1, and (F) osgnat1 osgnat2. Arrowheads and arrows indicate the second and fourth leaf blades, respectively. $(\mathrm{G})$ Changes in leaf number during vegetative development. $\mathrm{H}-$ M) Localization of PLA1 $(\mathrm{H}, \mathrm{K}), \operatorname{OsBE1}(\mathrm{I}, \mathrm{L})$, and OsGNAT1 $(\mathrm{J}, \mathrm{M})$ mRNAs in longitudinal $(\mathrm{H}-$ $\mathrm{J})$ and cross $(\mathrm{K}-\mathrm{M})$ sections of the shoot apex of 10-day-old seedlings. Bars: $100 \mu \mathrm{m}$. 


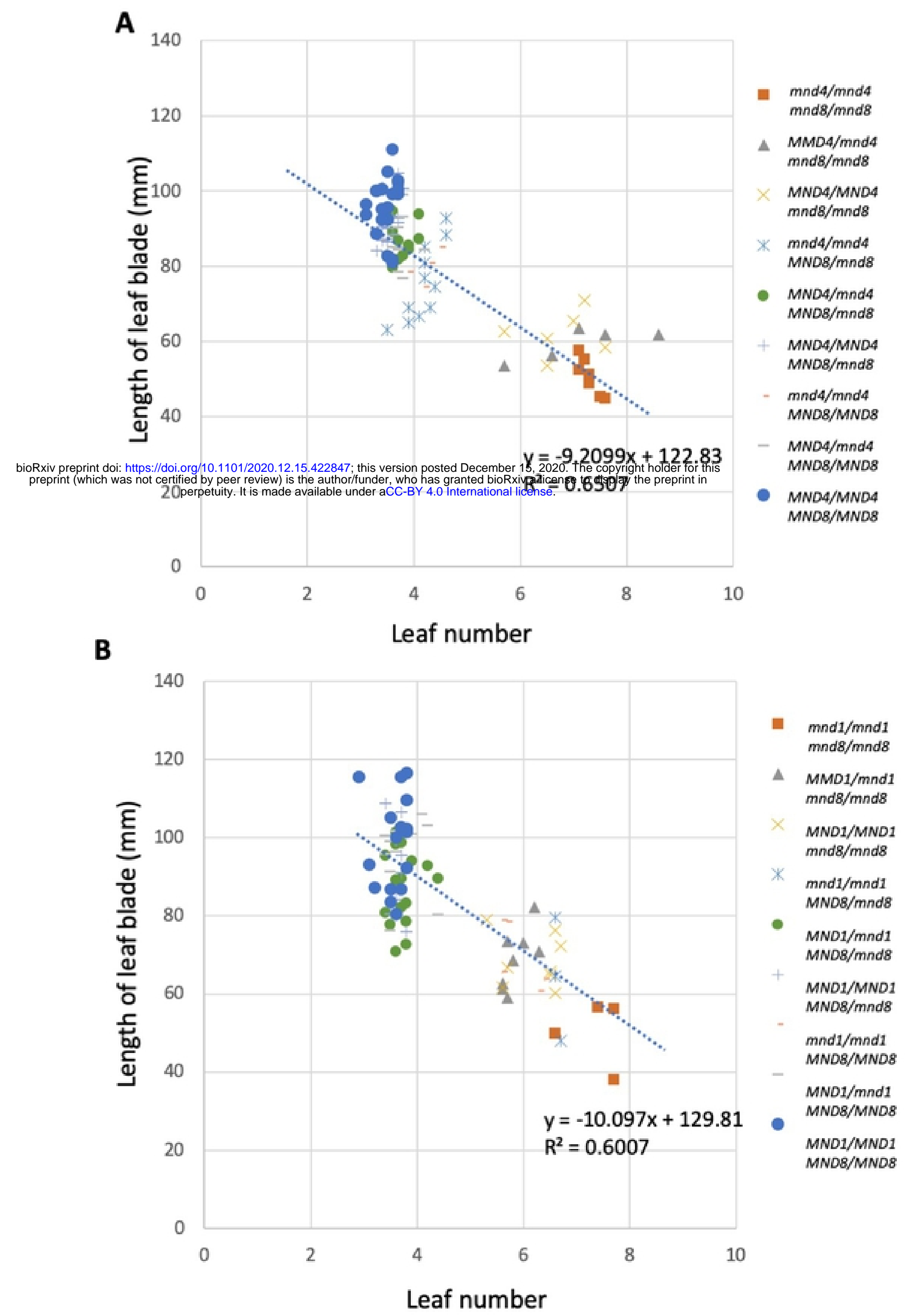

Fig 7. Relationship between leaf number and leaf-blade length. (A, B) Scatter plots of leaf number at 2 months after germination and the length of the second leaf blade in segregated plants from $m n d 4_{\text {oum } 169} \times m n d 8_{\text {oum } 165}$ (A) and $m n d 1_{\text {oux } 051} \times m n d 8_{\text {oum } 165}(\mathrm{~B})$ crossings. The linear regression line and coefficient of determination $\left(\mathrm{R}^{2}\right)$ are indicated. 


\section{Fig 6}

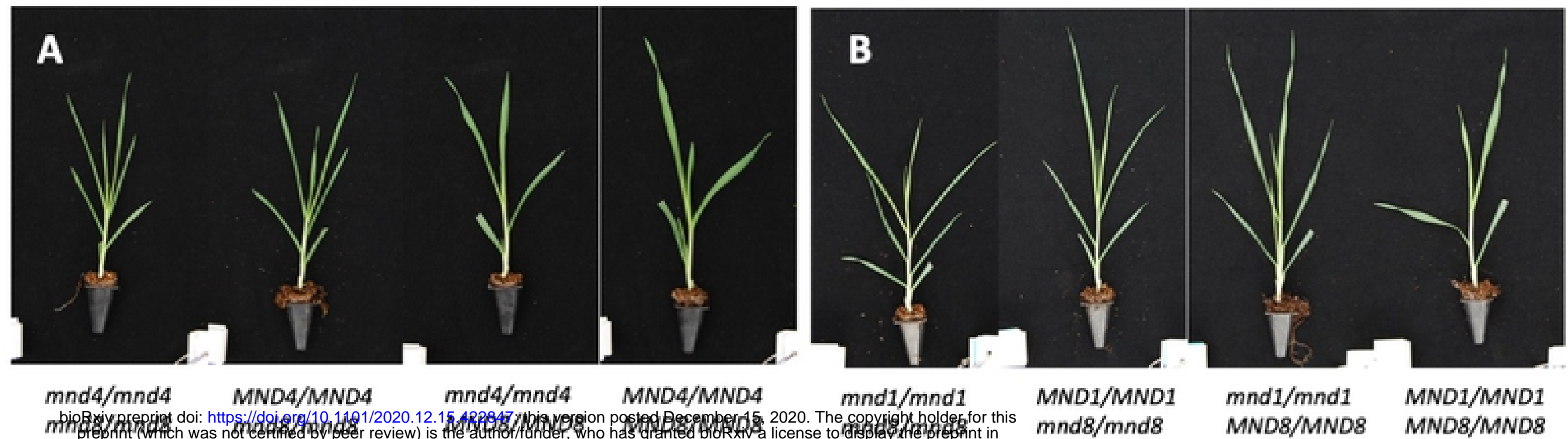

C

C

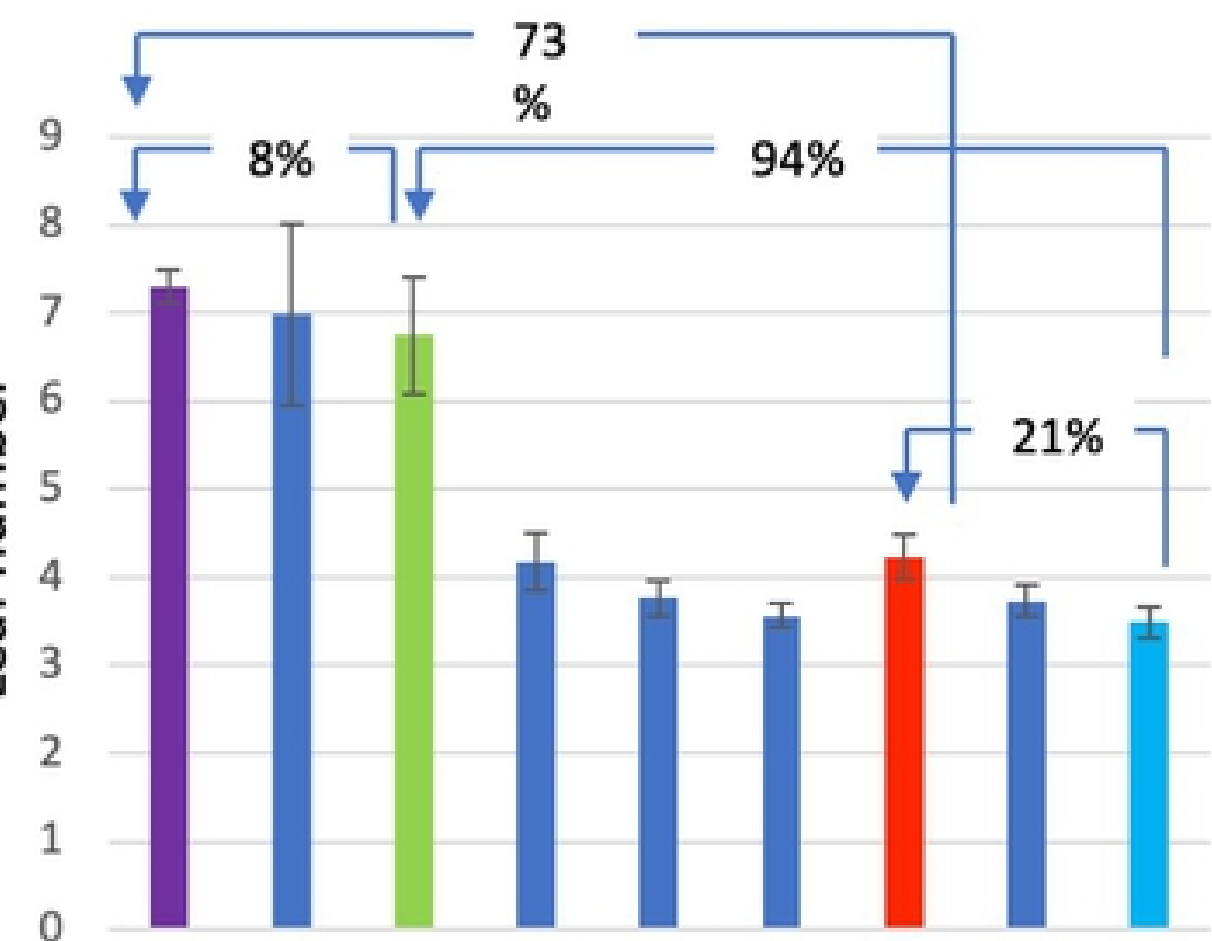

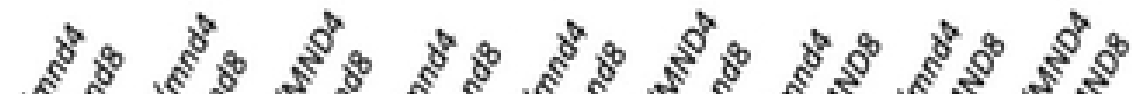

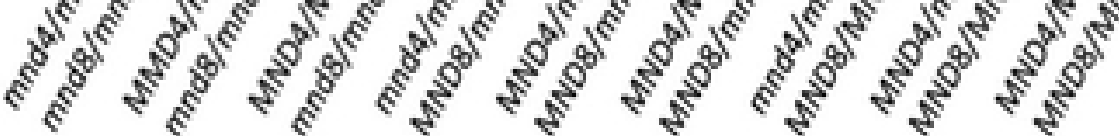

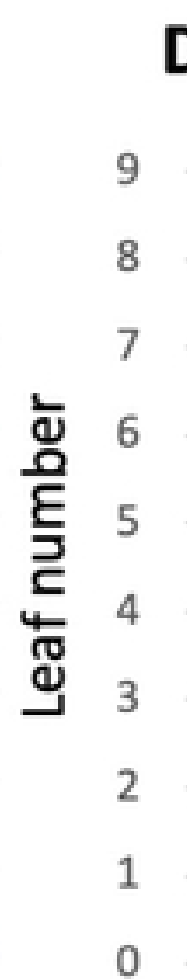

D
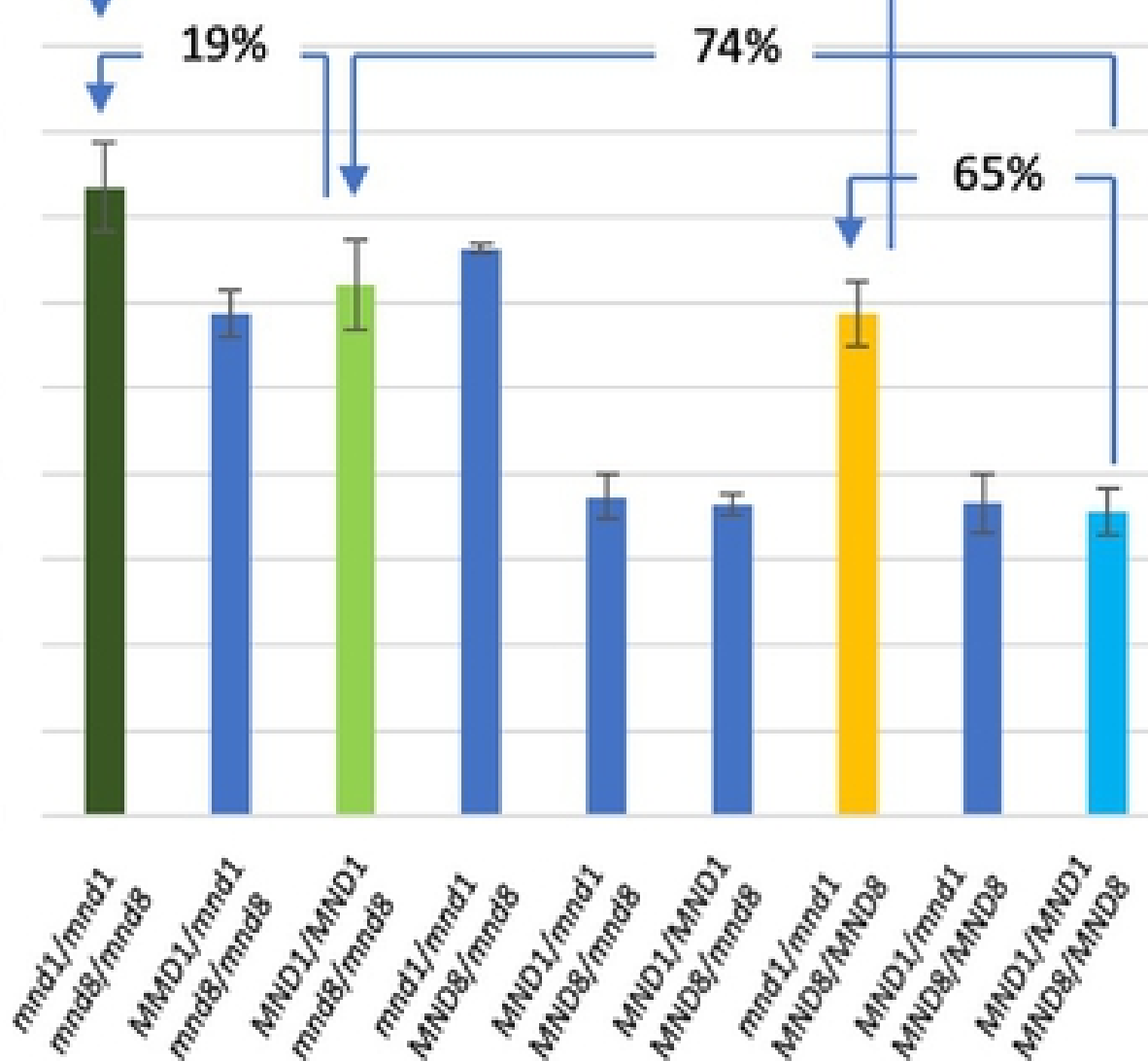

Fig 6. Effect of $m$ nd double mutations on leaf number. (A, B) Seedling phenotypes of single and double mutants of $m n d 4_{\text {OuM169 }}$ and $m n d 1_{\text {oux } 051}$ (A) and $m n d 4_{\text {OUM } 169}$ and $m n d 8_{\text {OuM165 }}$ (B) at 2 months after germination. Genotypes are indicated below. (C, D) Effect of $m n d 4_{\text {Oum169 }}$ and $m n d 1_{\text {oux } 051}$ (C) as well as $m n d 4_{\text {oum169 }}$ and mnd $8_{\text {oum165 }}$ (D) alleles on leaf number. Arrows and percentages indicate the effect of homozygotic mutations of mnds on the rate of increase in leaf number. 
Fig 5
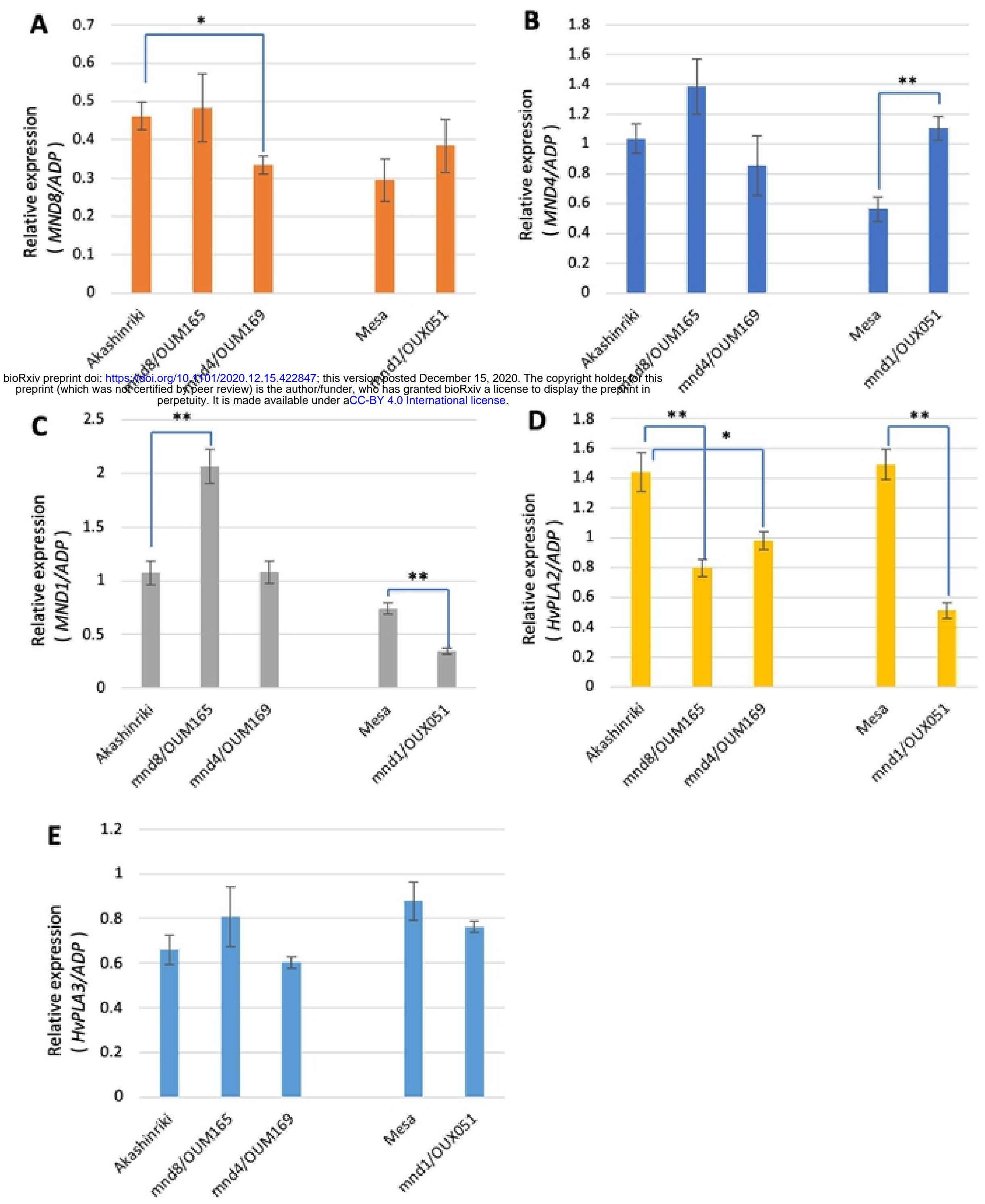

Fig 5. Expression change in MND and HvPLA in mnd mutant backgrounds. Relative expression levels of MND8 (A), MND4 (B), MND1 (C), HvPLA2 (D), and HvPLA3 (E). ADPribosylation factor 1-like protein (ADP) was used as the internal control. Double and single asterisks indicate a statistically significant difference compared to the wild type (WT; $t$-test, $\mathrm{P}<$ 0.01 and 0.05 , respectively). 


\section{Fig 4}
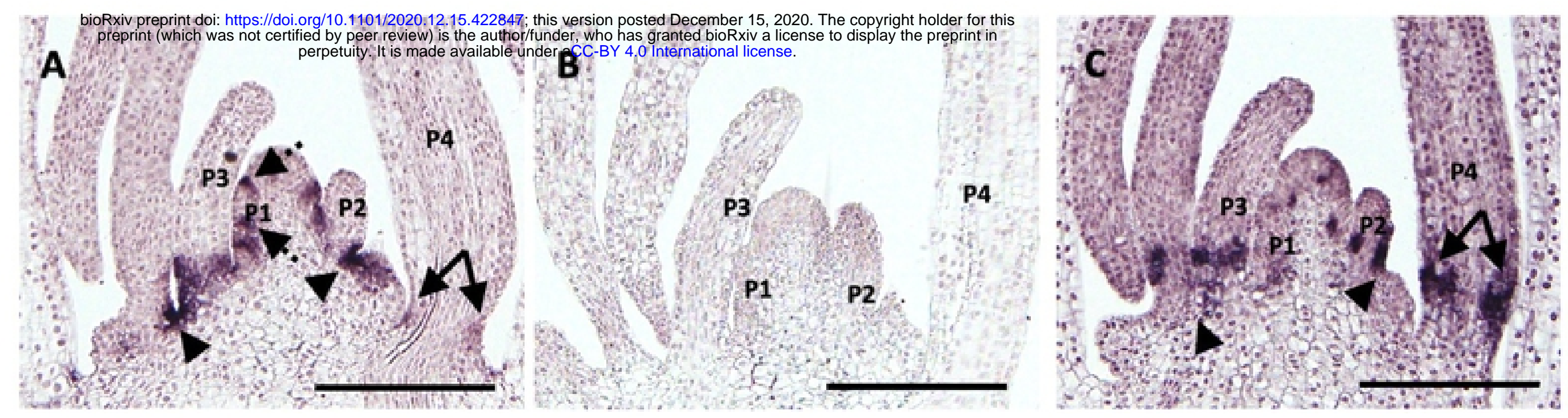

Fig 4. Expression pattern of the three $M N D$ genes in the shoot apex at 10 days after germination. (A) MND4, (B) MND8, and (C) MND1. The P1-P4 leaf primordia are labeled. Arrowheads indicate gene expression at the boundaries between leaf primordia. The dashed arrow in (A) indicates expression at the boundary between the shoot apical meristem and P1 leaf primordium. Two-headed arrows indicate expression at the leaf base. Note the relative position of expression at the leaf base differs between (A) and (C). Bars: $200 \mu \mathrm{m}$. 
Fig 3

A

MND4 (HORVU5Hr1G081060)

$(1,832 \mathrm{bp})$

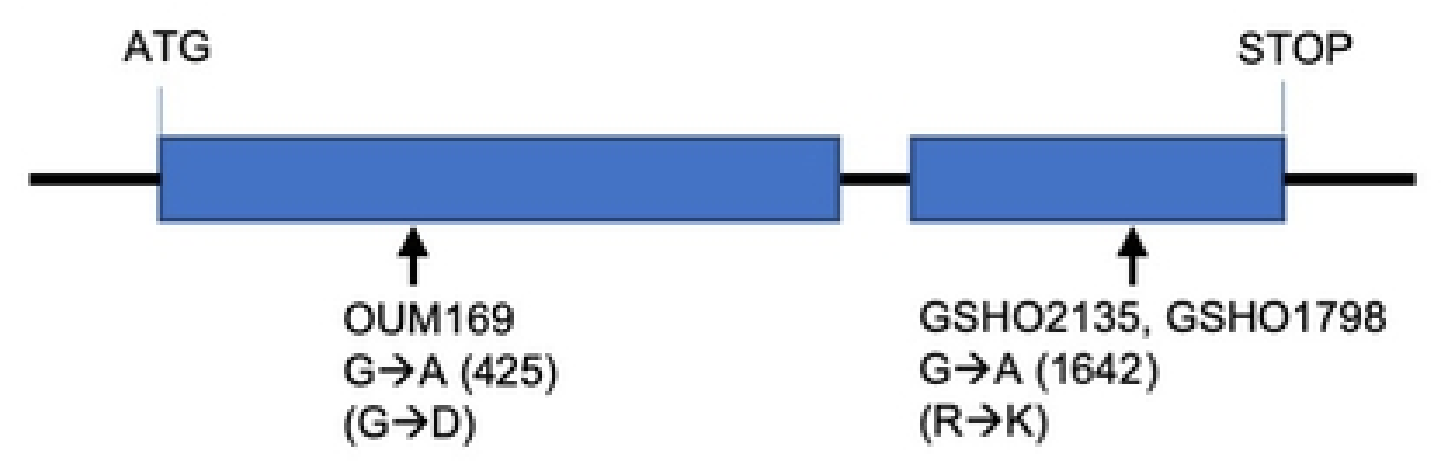

bioRxiv preprint doi: https://doi.org/10.1101/2020.12.15.422847; this version posted December 15, 2020. The copyright holder for this

(which was not certified by peer review) is the author/funder who has granted bioRxiv a license to display the preprint in

B

MND8 (HORVU5Hr1G118820)

(3,355bp)

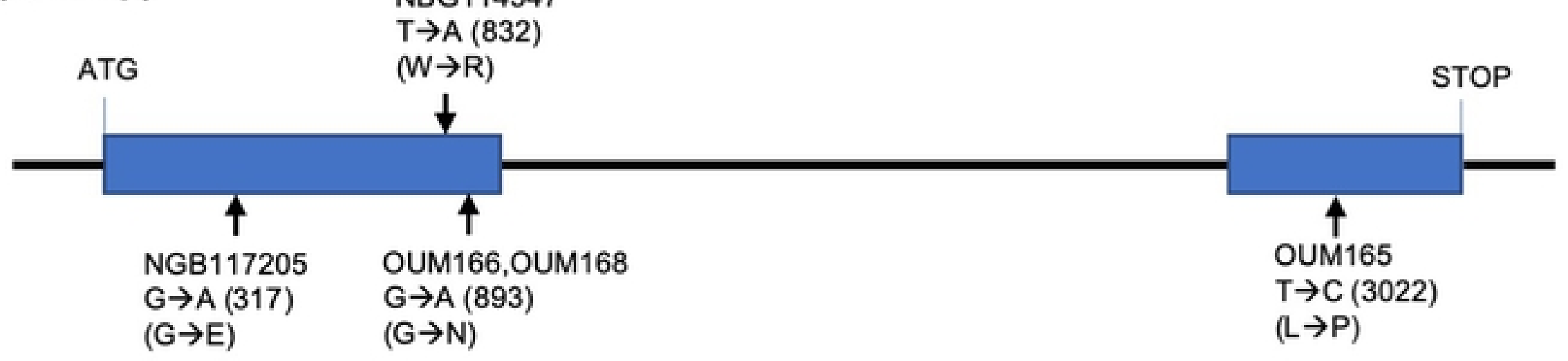

C MND1 (HORVU7Hr1G113480)

(1,693bp) SM5

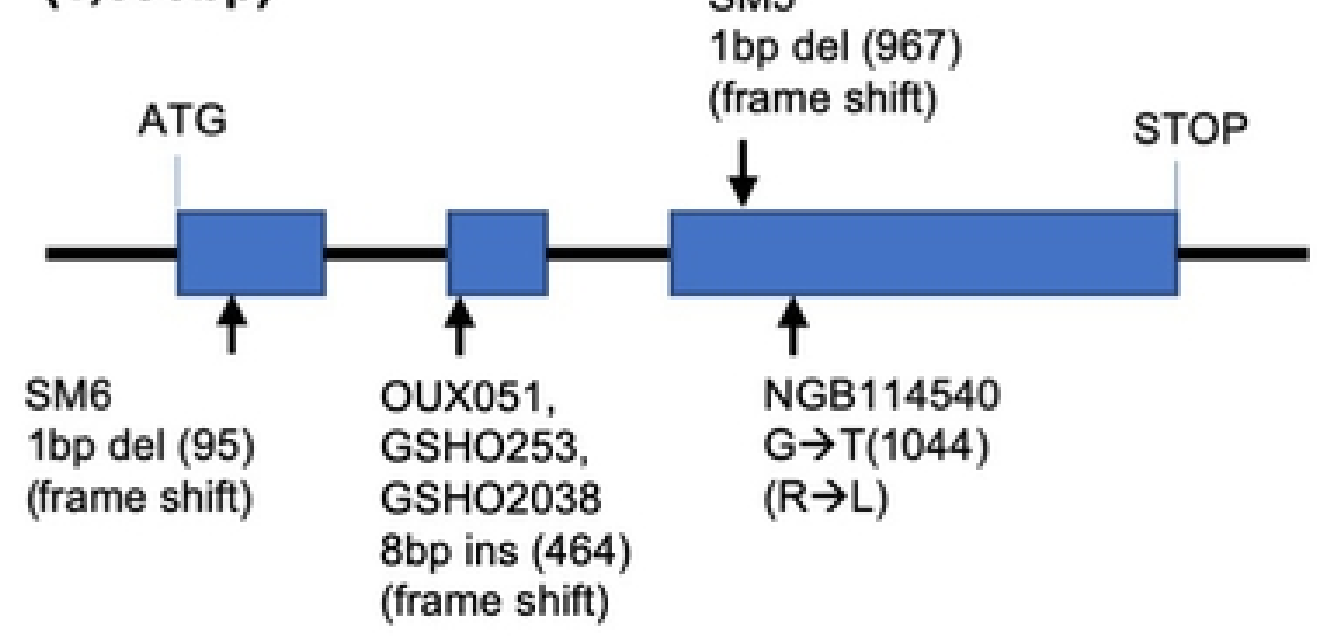

$1 \mathrm{kbp}$

Fig 3. Genomic structure of MND genes. $(A-C)$ Genomic structure and mutation points of MNDs. (A) MND4, (B) MND8, and (C) MND1. Boxes indicate exons, arrows indicate mutation points. 
Fig 2

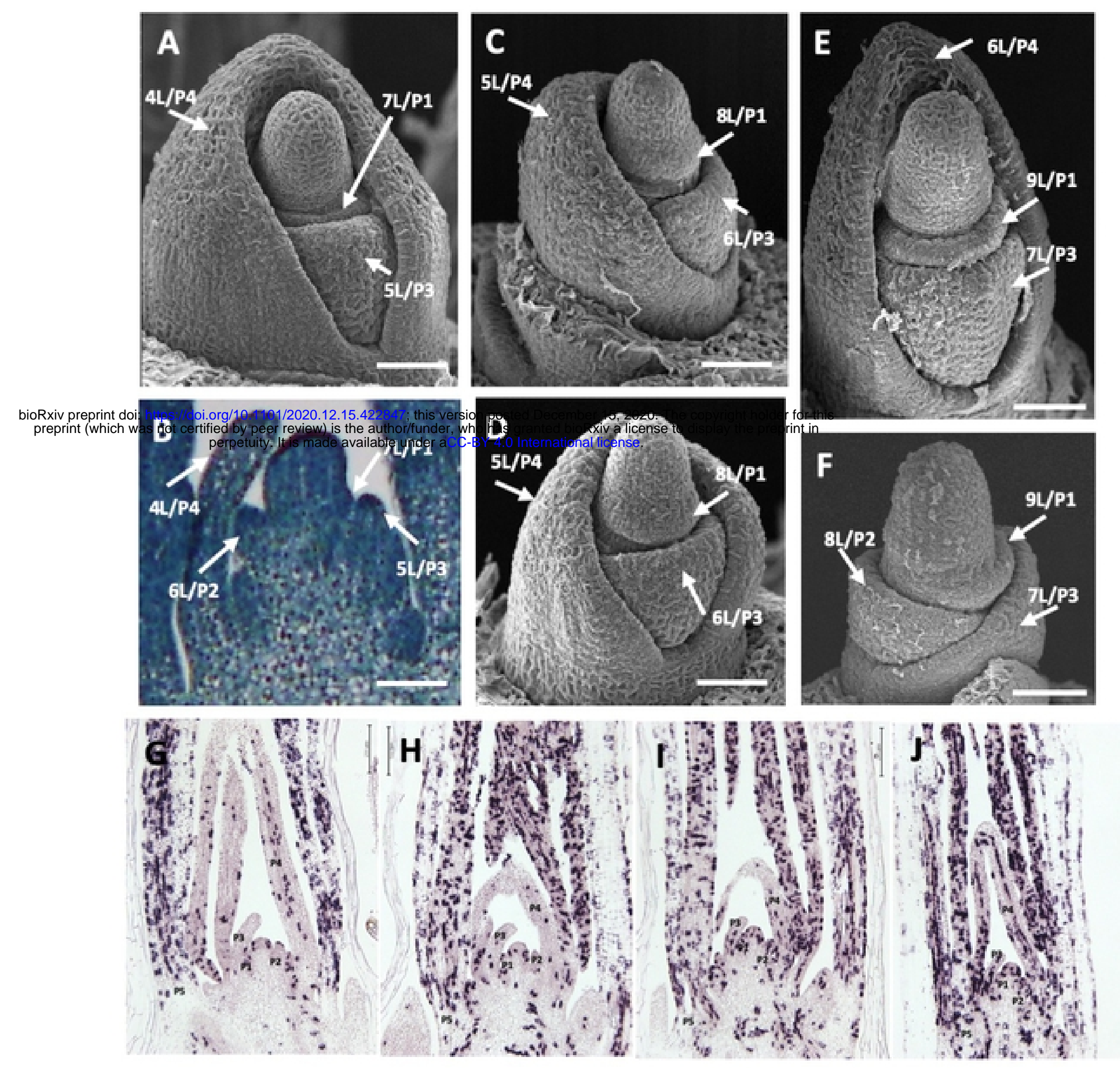

Fig 2. Spatial relationship between leaf-primordium stage and cell-division activity in mnd mutants. (A, $\mathrm{C}-\mathrm{F}$ ) Scanning electron micrographs of the shoot apex of $m$ nd mutants at 2 weeks after germination. (A) Shoot apex of Akashinriki. (B) Longitudinal section of the shoot apex of Akashinriki corresponding to (A). Shoot apices in $m n d 8_{\text {oum165 }}(\mathrm{C})$, $m n d 4_{\text {OUM } 169}$ (D), and $m n d 1_{\text {oux051 }}$ (E). (F) Shoot apex of $m n d 1_{\text {oux } 051}$ from which the 6L/P4 primordium was removed. $x L$ indicates the $x^{\text {th }}$ leaf and $\mathrm{Px}$ is the order of leaf emergence from the shoot apical meristem. (G-J) Expression pattern of histone $\mathrm{H} 4$ in the shoot apex of wild-type and $m n d$ mutants at 10 days after germination according to in situ hybridization. (G) Akashinriki, (H) mnd $8_{\text {oum } 165}$ ( $(\mathrm{I}) m n d 4_{\text {oum } 169}$, and $(\mathrm{J}) m n d 1_{\text {oux } 051}$. Bars: $50 \mu \mathrm{m}$ in $\mathrm{A}-\mathrm{F}$ and $200 \mu \mathrm{m}$ in $\mathrm{G}-\mathrm{J}$. 
Fig 1
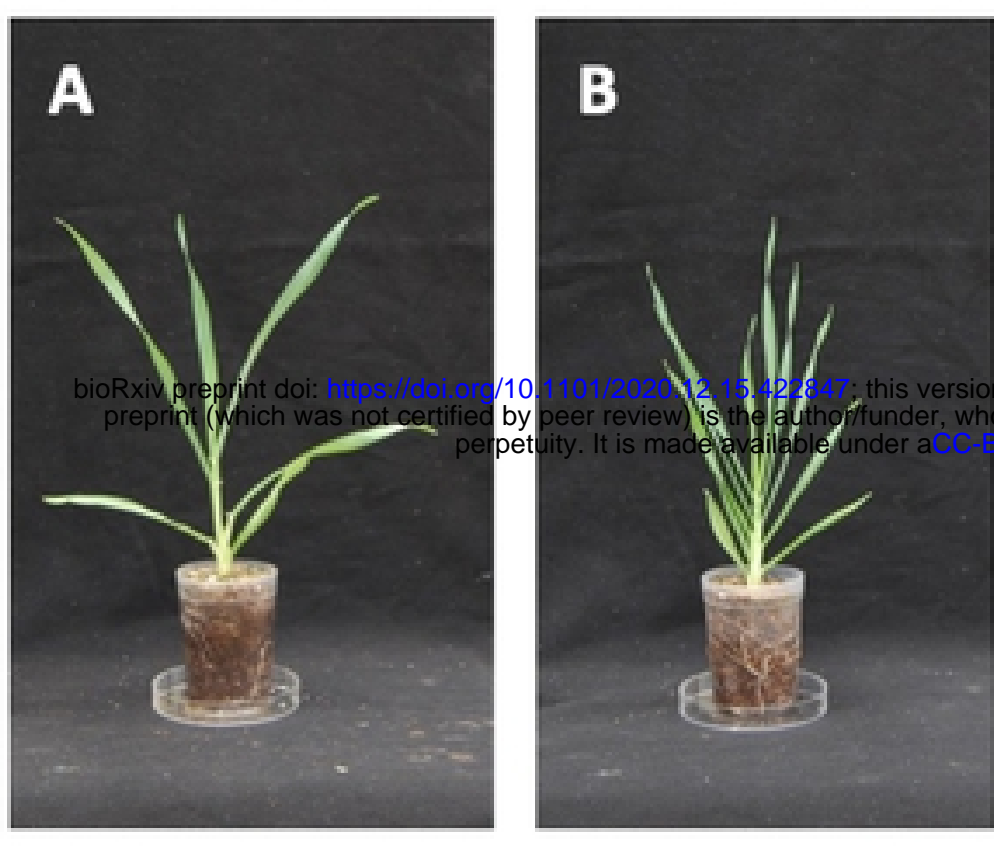

$$
\begin{array}{r}
16.0 \\
15.0 \\
14.0
\end{array}
$$
posted December 15, 2020. The copyright holder for this 4.0 International license.
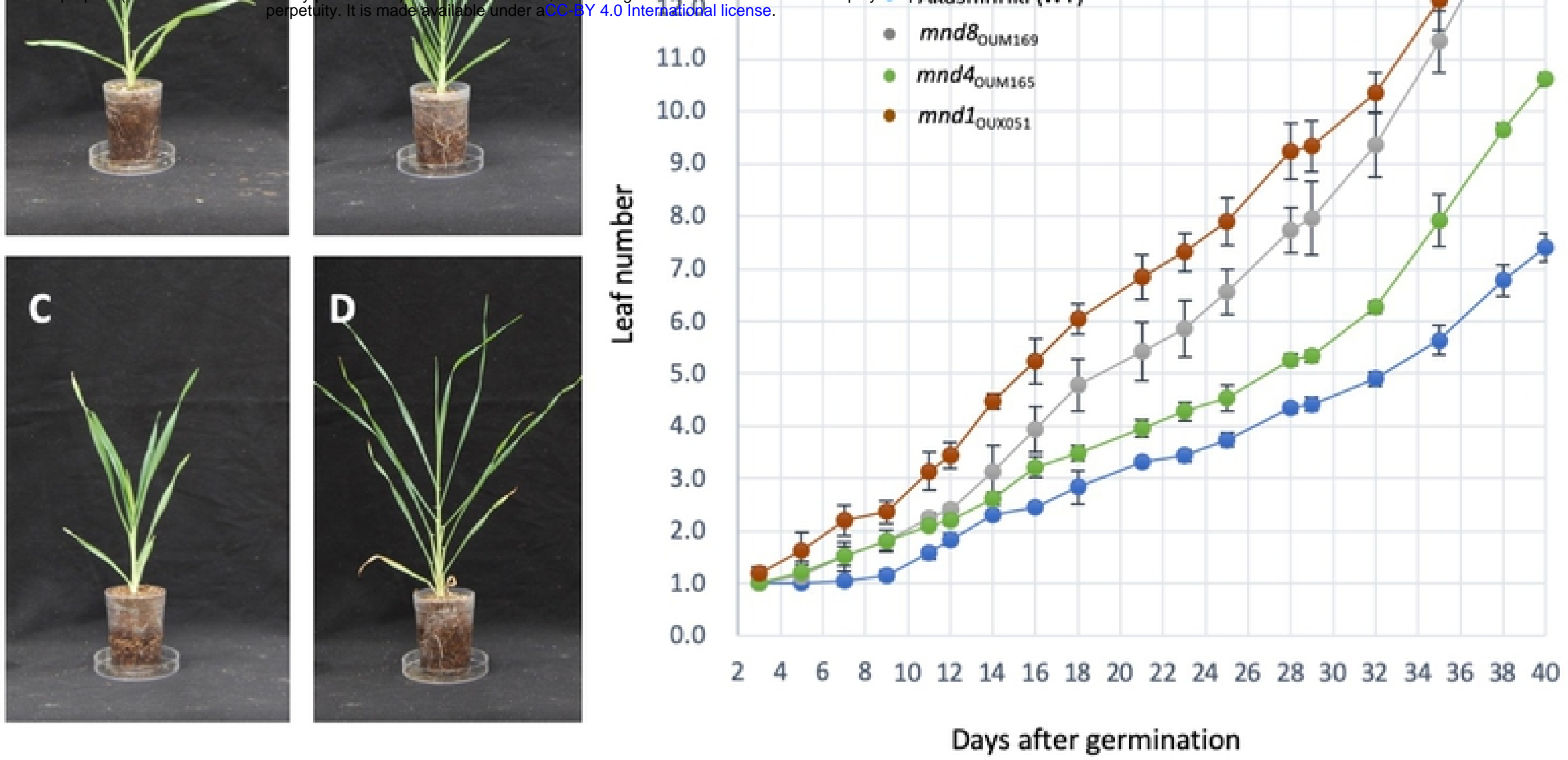

Fig 1. Vegetative phenotypes of $m n d$ mutants. (A-D) Seedlings of the wild-type and $m n d$ mutants at 1 month after germination. (A) Akashinriki, (B) mnd $8_{\text {oum } 165}$, (C) $m n d 4_{\text {oum } 169,}$, and (D) $m n d 1_{\text {ouxo51 }}$. (E) Changes in leaf number during vegetative development. 